\title{
Sigma-2 Receptors Play a Role in Cellular Metabolism: Stimulation of Glycolytic Hallmarks by CM764 in Human SK-N-SH Neuroblastoma ${ }^{\mathbf{S}}$
}

\author{
Hilary Nicholson, Christophe Mesangeau, Christopher R. McCurdy, and Wayne D. Bowen \\ Department of Molecular Pharmacology, Physiology, and Biotechnology, Brown University, Providence, Rhode Island (H.N., \\ W.D.B.); and Department of BioMolecular Sciences, School of Pharmacy, University of Mississippi, University, Mississippi (C.M., \\ C.R.M.)
}

Received August 3, 2015; accepted November 13, 2015

\begin{abstract}
Sigma-2 receptors are attractive antineoplastic targets due to their ability to induce apoptosis and their upregulation in rapidly proliferating cancer cells compared with healthy tissue. However, this role is inconsistent with overexpression in cancer, which is typically associated with upregulation of prosurvival factors. Here, we report a novel metabolic regulatory function for sigma-2 receptors. CM764 [6-acetyl-3-(4-(4-(2amino-4-fluorophenyl)piperazin-1-yl)butyl)benzo[d]oxazol-2 $(3 H)$-one] binds with $K_{\mathrm{i}}$ values of $86.6 \pm 2.8$ and $3.5 \pm 0.9 \mathrm{nM}$ at the sigma- 1 and sigma-2 receptors, respectively. CM764 increased reduction of MTT [3-[4,5 dimethylthiazol-2-yl]-2,5 diphenyltetrazolium bromide] in human SK-N-SH neuroblastoma compared with untreated cells, an effect not due to proliferation. This effect was attenuated by five different sigma antagonists, including CM572 [3-(4-(4-(4-fluorophenyl)piperazin-1-yl)butyl)-6isothiocyanatobenzo[d]oxazol-2(3H)-one], which has no significant
\end{abstract}

affinity for sigma-1 receptors. This effect was also observed in MG-63 osteosarcoma and HEK293T cells, indicating that this function is not exclusive to neuroblastoma or to cancer cells. CM764 produced an immediate, robust, and transient increase in cytosolic calcium, consistent with sigma-2 receptor activation. Additionally, we observed an increase in the total $\mathrm{NAD}^{+}$/NADH level and the ATP level in CM764-treated SK-N$\mathrm{SH}$ cells compared with untreated cells. After only 4 hours of treatment, basal levels of reactive oxygen species were reduced by $90 \%$ in cells treated with CM764 over untreated cells, and HIF $1 \alpha$ and VEGF levels were increased after 3-24 hours of treatment. These data indicate that sigma-2 receptors may play a role in induction of glycolysis, representing a possible prosurvival function for the sigma-2 receptor that is consistent with its upregulation in cancer cells compared with healthy tissue.

\section{Introduction}

The sigma receptors comprise a pharmacologically defined family of membrane bound receptors that bind compounds from a variety of structural classes. The sigma-1 receptor is a $25-\mathrm{kDa}$ protein that demonstrates stereoselectivity for $(+)$ benzomorphans and is known to promote cell survival (Hayashi and Su 2003, 2007; Tsai et al., 2009). The sigma-2

This work was supported by the National Institutes of Health National Institute of General Medical Sciences T32 Predoctoral Pharmacology Training Grants Program [Grant 1-T32 GM077995-01A2] (H.N.); National Institutes of Health National Institute of General Medical Sciences Initiative for Maximizing Student Development Program [Grant R25 GM083270] (HN); Brown University Pharmacia Pre-doctoral Fellowship in Pharmacology (H.N.); National Institutes of Health National Institute on Drug Abuse [Grant R01 DA023205] (C.M., C.R.M.); National Institutes of Health National Institute of General Medical Sciences [Grant P20 GM104932] (C.M., C.R.M.); and Upjohn Professorship in Pharmacology, Brown University (W.D.B.)

This work has been previously presented in part at the Society for Neuroscience Annual Meeting 2014 (299.17).

dx.doi.org/10.1124/jpet.115.228387.

S This article has supplemental material available at jpet.aspetjournals.org. receptor is a $21.5-\mathrm{kDa}$ protein that binds (+)-benzomorphans poorly and is significantly upregulated in rapidly proliferating tumors compared with noncancerous tissue (Hellewell and Bowen 1990; Vilner et al., 1995; Wheeler et al., 2000). The presence of sigma-2 receptors has been validated in an extensive list of human and rodent cancer cell lines and tumors, and thus a ubiquitous role in cancer biology has been proposed (Wheeler et al., 2000; Mach et al., 2013).

Upon activation, the sigma-2 receptor induces apoptotic cell death (Crawford and Bowen 2002; Zeng et al., 2012, 2014). A variety of pathways have been described in response to sigma2 receptor activation, indicating that there exists more than one mechanism of sigma-2 receptor-induced cell death (Zeng et al., 2012). Furthermore, discrete ligands induce independent apoptotic pathways even within a cell type, again suggesting the ability of the sigma-2 receptor to activate multiple signaling pathways (Crawford and Bowen 2002; Cassano et al., 2009; Zeng et al., 2012; Česen et al., 2013).

The sigma-2 receptor has received attention for its potential use as a chemotherapeutic target. The significant

ABBREVIATIONS: CM572, 3-(4-(4-(4-fluorophenyl)piperazin-1-yl)butyl)-6-isothiocyanatobenzo[d]oxazol-2(3H)-one; CM764, 6-acetyl-3-(4-(4-(2amino-4-fluorophenyl)piperazin-1-yl)butyl)benzo[d]oxazol-2(3H)-one; DCFDA, 2',7'-dichlorofluorescin diacetate; HBSS, Hanks' balanced salt solution; MTT, 3-[4,5 dimethylthiazol-2-yl]-2,5 diphenyltetrazolium bromide; ROS, reactive oxygen species; RT, room temperature; SN79, 6-acetyl3-(4-(4-(4-fluorophenyl)piperazin-1-yl)butyl)benzo[d]oxazol-2(3H)-one; TBS, Tris-buffered saline; TCA, tricarboxylic acid. 
upregulation of sigma-2 receptors in cancer compared with healthy tissue makes it a naturally cancer-selective target, and it is currently being examined clinically for diagnostic tumor imaging (Mach et al., 2013; Shoghi et al., 2013). The induction of apoptosis upon activation combined with endogenous cancer cell selectivity makes the sigma-2 receptor an attractive target for chemotherapeutic intervention. We have recently shown that the irreversible sigma-2 receptor par tial agonist CM572 [3-(4-(4-(4-fluorophenyl)piperazin-1yl)butyl)-6-isothiocyanatobenzo[ $d]$ oxazol-2(3H)-one] selectively induces cell death in neuroblastoma, pancreatic, and breast cancer cell lines compared with effects in normal epithelial melanocytes or normal breast epithelial cells (Nicholson et al., 2015). However, the wide variety of apoptotic mechanisms induced by sigma-2 receptor activation combined with a disparity among criteria for defining functional classes of sigma-2 receptor ligands makes studying the efficacy of such drugs difficult.

One intrinsic question about sigma-2 receptors that has yet to be extensively addressed surrounds their endogenous function. The endogenous ligand for sigma-2 receptors has yet to be elucidated, thus all hypotheses surrounding sigma-2 receptor function are based on observations collected through manipulation with synthetic agents. The observed apoptotic response to treatment with sigma-2 receptor ligands is widely supported. However, it is inconsistent with upregulated expression in rapidly proliferating cancer cells. This counterintuitive role is further called into question when coupled with the significant expression of sigma-2 receptors in some noncancerous tissues such as liver and kidney (Hellewell et al., 1994), which indicates a role for sigma-2 receptors outside of cancer cell proliferation.

Evidence for a nonapoptotic function of sigma-2 receptors is not yet extensive; however, examples of such activity do exist. For example, one criterion for classification of a sigma-2 receptor agonist is stimulated transient release of calcium from thapsigargin-sensitive pools in the endoplasmic reticulum (Vilner and Bowen 2000; Cassano et al., 2009). However, this calcium signal is not a trigger for apoptosis, since cells appear normal if the ligand is removed after the transient returns to baseline (unpublished observation). In addition, there are also sigma-2 ligands that produce a calcium signal, but do not have the ability to kill cells. The sigma-2 receptor ligand, SN79 [6-acetyl-3-(4-(4-(4-fluorophenyl)piperazin-1-yl) butyl)benzo[d] oxazol-2(3H)-one] (Kaushal et al., 2011, 2012) produces a small calcium signal in SK-N-SH neuroblastoma cells, but is unable to induce significant levels of cytotoxicity even at high doses (Garcia 2012). Based on such data we have proposed that the sigma- 2 receptor may signal to pathways that bifurcate to those that result in apoptotic cell death and those that result in as yet uncharacterized nonapoptotic effects (Garcia and Bowen, 2010; Garcia 2012).

Recently, it was proposed that progesterone receptor membrane component-1 (PGRMC1) is the putative sigma-2 receptor binding site (Xu et al., 2011). In MCF-7 cells, PGRMC1 mediates a signal that stimulates proliferation and angiogenesis-related effects (Neubauer et al., 2009), further suggesting a nonapoptotic function for ligands binding PGRMC1 or the sigma-2 receptor, whether identical or pharmacologically related. Here, we report a novel nonapoptotic, metabolically stimulative function for the sigma-2 receptor, discovered through intervention with
CM764 [6-acetyl-3-(4-(4-(2-amino-4-fluorophenyl)piperazin1-yl)butyl)benzo[d] oxazol-2(3H)-one], a novel derivative of SN79. This may suggest a divergent role of relevance to sigma-2 receptor upregulation.

\section{Materials and Methods}

Radioligand Binding Assay. Rat liver membrane homogenates were used for receptor binding assays with slight modification to the previously reported procedure (Hellewell et al., 1994). Frozen rat livers (BioChemed, Winchester, VA) were thawed and homogenized for membrane preparation as previously described (Hellewell et al., 1994). Membrane protein $(150 \mu \mathrm{g})$ was incubated with $3 \mathrm{nM}\left[{ }^{3} \mathrm{H}\right](+)$ pentazocine (Perkin Elmer, Waltham, MA) (sigma-1 receptor condition) or $5 \mathrm{nM}\left[{ }^{3} \mathrm{H}\right]-1,3$-di-o-tolylguanidine (Perkin Elmer) and $100 \mathrm{nM}$ unlabeled (+)-pentazocine to mask sigma-1 receptors (sigma-2 receptor condition) with various concentrations of CM764 for 120 minutes at $25^{\circ} \mathrm{C}$ in $20 \mathrm{mM}$ HEPES $\mathrm{pH} 7.4$ with gentle shaking. Nonspecific binding was measured in the presence of $10 \mu \mathrm{M}$ haloperidol. Membranes were collected by filtration using a Brandel Cell Harvester (Brandel, Gaithersburg, MD) onto glass fiber filters that were presoaked in $0.5 \%$ polyethyleneimine for 30 minutes at room temperature (RT). Ice-cold $10 \mathrm{mM}$ Tris-HCl, $\mathrm{pH} 7.4$ was used to terminate reactions using $5 \mathrm{ml}$ buffer followed by two $5 \mathrm{ml}$ buffer washes. The $K_{\mathrm{i}}$ values were determined by competition binding assay and data analyzed using GraphPad Prism 6 (GraphPad Software, La Jolla, CA) with $K_{\mathrm{d}}=17.9 \mathrm{nM}$ for $\left[{ }^{3} \mathrm{H}\right]-1,3$-di-o-tolylguanidine at sigma-2 receptors and $K_{\mathrm{d}}=7.5 \mathrm{nM}$ for $\left[{ }^{3} \mathrm{H}\right](+)$-pentazocine at sigma-1 receptors in rat liver membrane homogenates.

Cell Culture. Human SK-N-SH neuroblastoma cells were obtained from ATCC (Manassas, VA) and were cultured in minimal essential medium (Gibco, Grand Island, NY) with $10 \%$ fetal bovine serum and $10 \mathrm{mg} / \mathrm{l}$ human insulin (Gibco) in humidified atmosphere at $37^{\circ} \mathrm{C}$ and $5 \% \mathrm{CO}_{2}$. HEK $293 \mathrm{~T} / 17$ human embryonic kidney cells were a generous gift from E. Oancea (Brown University, Providence, RI), and human MG-63 osteosarcoma cells were a generous gift from E. Darling (Brown University). Both additional cell types were cultured in the same way as described for SK-N-SH neuroblastoma. Cells were passaged at $70 \%$ confluency.

MTT [3-[4,5 Dimethylthaizol-2-yl]-2,5 Diphenyltetrazolium Bromide] Cell Viability Assay. Cell viability was measured by MTT assay (Trevigen, Gaithersburg, MD) according to manufacturer's specifications. Cells were plated at 15,000 cells/well (SK-N$\mathrm{SH}$ ) or 10,000 cells/well (HEK 293 T/17, MG-63) in a 96-well plate and allowed to attach overnight. Cells were then treated for 24 hours prior to addition of $10 \mu \mathrm{l}$ MTT reagent, which was allowed to be metabolized into colored formazan crystals for 3 hours. A $100 \mu \mathrm{l}$ aliquot of MTT detergent reagent was then added and formazan crystals and cell membranes were solubilized for 2 hours prior to reading absorbance at $570 \mathrm{~nm}$. Data were analyzed in Microsoft Excel.

CyQUANT Cell Proliferation Assay. Cellular proliferation was measured using the CyQUANT Cell Proliferation Assay Kit (Life Technologies, Grand Island, NY) according to manufacturer's specifications. For the experiments cells were plated in 96 -well plates at 15,000 cells/well for 24-48 hours or 10,000 cells/well for 72-96 hours. Cells were allowed to attach overnight prior to treatment with $10 \mu \mathrm{M}$ CM764 or fresh media without ligand (control). Media with or without ligand was replaced every 24 hours. After the indicated time, cells were washed once with phosphate-buffered saline, and then the plate was inverted and blotted dry onto a Kimwipe (Kimberly-Clark Professional, Roswell, GA) by gentle tapping and frozen at $-80^{\circ} \mathrm{C}$ for at least 24 hours. Plates were then thawed to RT and stained with 1X CyQUANT GR dye (which exhibits enhanced fluorescence when bound to nucleic acids) in cell lysis buffer for 5 minutes and protected from light prior to measurement of fluorescence at 480-nm excitation/ 520-nm emission. 
TABLE 1

Sigma receptor ligands and their affinities and selectivities

\begin{tabular}{|c|c|c|c|c|c|}
\hline Common Name & Chemical Name & $\begin{array}{l}\text { Sigma-1 Receptor } \\
\text { Affinity }\end{array}$ & $\begin{array}{l}\text { Sigma-2 Receptor } \\
\text { Affinity }\end{array}$ & $\begin{array}{l}\text { Sigma-2 Receptor } \\
\text { Selectivity (fold) }\end{array}$ & Reference \\
\hline & & $n M$ & $n M$ & & \\
\hline SN79 & $\begin{array}{l}\text { 6-acetyl-3-(4-(4-(4-fluorophenyl)piperazin-1-yl) } \\
\text { butyl)benzo[d]oxazol-2(3H)-one }\end{array}$ & 27 & 7 & 4 & Kaushal et al. (2011) \\
\hline CM572 & $\begin{array}{l}\text { 3-(4-(4-(4-fluorophenyl)piperazin-1-yl) } \\
\text { butyl)-6-isothiocyanatobenzo[ }[d] \text { oxazol-2(3H)-one }\end{array}$ & $>10,000$ & 14.6 & $>685$ & Nicholson et al. (2015) \\
\hline BD1047 & $\begin{array}{l}\mathrm{N}^{\prime} \text {-[2-(3,4-dichlorophenyl)ethyl]-N,N, } \\
\text { N'-trimethylethane-1,2-diamine }\end{array}$ & 0.93 & 47 & 0.02 & Matsumoto et al. (1995) \\
\hline NE100 & $\begin{array}{l}\text { 4-methoxy-3-(2-phenylethoxy)-N, } \\
\text { N-dipropylbenzeneethanamine }\end{array}$ & 1.54 & 84.7 & 0.02 & Chaki et al. (1994) \\
\hline BD1063 & $\begin{array}{l}\text { 1-[2-(3,4-dichlorophenyl) } \\
\text { ethyl]-4-methylpiperazine }\end{array}$ & 9.15 & 449 & 0.02 & Matsumoto et al. (1995) \\
\hline (+)-Pentazocine & $\begin{array}{l}\text { 2-dimethylallyl-5, } \\
\text { 9-dimethyl-2'-hydroxybenzomorphan }\end{array}$ & 7.5 & 1,542 & 0.005 & Hellewell et al. (1994) \\
\hline
\end{tabular}

Calcium Release Assay. Fura-2 ratiometric assay was used to measure intracellular calcium in SK-N-SH neuroblastoma. Cells were seeded at 20,000 cells/well and allowed to attach overnight prior to washing twice with Hanks' balanced salt solution (HBSS) and loading for 60 minutes with $2.47 \mu \mathrm{M}$ fura-2 acetoxymethyl ester (Invitrogen, Grand Island, NY) in $0.065 \%$ pluronic acid in HBSS. Cells were then washed twice with HBSS prior to injecting the well with the indicated ligand. Stock solutions for injection were adjusted such that the injection volume was $10 \mu \mathrm{l}$, injected onto $90 \mu \mathrm{l} \mathrm{HBSS}$ in the well for a final total volume of $100 \mu \mathrm{l}$. The fura- 2 fluorescence ratio was measured with excitation at 340 and $380 \mathrm{~nm}$ and emission at $510 \mathrm{~nm}$ using a Perkin Elmer Victor V plate reader. A baseline ratio was determined prior to injection by measuring 25 readings over 43 seconds, after which the $10 \mu \mathrm{l}$ injection was made and 100 readings were measured.

NAD $^{+}$/NADH Assay. $\mathrm{NAD}^{+}$and $\mathrm{NADH}$ were measured using the $\mathrm{NAD}^{+} / \mathrm{NADH}$ Quantification Colorimetric Kit from BioVision (Milpitas, CA), which allows for determination of total NAD, $\mathrm{NAD}^{+}$, and $\mathrm{NADH}$ from plated cells without the need for purification steps. Cells were plated in $35-\mathrm{mm}$ petri dishes at 200,000 cells/dish and allowed to attach overnight prior to treatment with $10 \mu \mathrm{M}$ CM764 or fresh media without ligand (control) for 24 hours. The $\mathrm{NAD}^{+} / \mathrm{NADH}$ assay was then performed according to the manufacturer's specifications. Cells were washed once with cold phosphate-buffered saline, dissociated with $2.5 \mathrm{mM}$ EDTA, pelleted by centrifugation at $223 \mathrm{~g}$ for 5 minutes, and extracted with $400-\mu l$ extraction buffer by two freeze/ thaw cycles of 20 minutes on dry ice and 10 minutes at RT. The extract was then pelleted by centrifugation at $37,500 \mathrm{~g}$ for 5 minutes and supernatant was collected. For NADH determination, $\mathrm{NAD}^{+}$was degraded by heating at $60^{\circ} \mathrm{C}$ for 30 minutes. Samples were incubated with reaction mix for 5 minutes prior to the addition of $10 \mu$ l developer, and then allowed to cycle for 4 hours. Absorbance was measured every hour at $450 \mathrm{~nm}$. NADt $\left(\mathrm{NADH}+\mathrm{NAD}^{+}\right)$and $\mathrm{NADH}$ levels were measured directly; the $\mathrm{NAD}^{+}$level was inferred to be the difference between NADt and NADH. Protein concentration was measured by BCA Assay (Pierce, Waltham, MA) and NADt/NADH/NAD ${ }^{+}$levels were adjusted for protein levels.

ATP Assay. Cellular ATP was measured using an ATP Colorimetric/Fluorometric Assay Kit (BioVision) according to manufacturer's specifications. Cells were plated in 35-mm petri dishes at 600,000 cells/well and allowed to attach overnight prior to treatment with $10 \mu \mathrm{M}$ CM764 or fresh media without ligand (control). After 24 hours, cells were washed once with phosphate-buffered saline, lysed, and immediately deproteinized with perchloric acid and neutralized with potassium hydroxide. A $50-\mu \mathrm{l}$ aliquot of deproteinized supernatant was incubated with reaction mix for 30 minutes at RT and protected from light. Fluorescence of the samples was read at 535-nm excitation/587-nm emission. Protein concentration was measured by BCA Assay (Pierce) and ATP levels were adjusted for protein levels.
Detection of Cellular Reactive Oxygen Species (ROS). Cells were plated in a black-sided 96-well plate at 25,000 cells/well and allowed to attach overnight. Cells were then washed once with HBSS and stained with $50 \mu \mathrm{M} \mathrm{2} 2^{\prime}, 7^{\prime}$-dichlorofluorescin diacetate (DCFDA) (Abcam, Cambridge, MA) in HBSS for 45 minutes in the dark at $37^{\circ} \mathrm{C}$. Cells were washed once with HBSS and treated with the indicated compound for 4 hours in phenol red-free media with $200 \mu \mathrm{g} / \mathrm{ml}$ $\alpha$-tocopherol as a negative control and $500 \mu \mathrm{M}$ tert-butyl hydrogen peroxide as a positive control. Fluorescence was measured at $485-\mathrm{nm}$ excitation/535-nm emission.

Western Blot. SK-N-SH neuroblastoma cells were plated in 35-mm petri dishes and allowed to attach overnight prior to treatment with $10 \mu \mathrm{M}$ CM764 for the indicated time. Cells were lysed in radioimmunoprecipitation assay buffer containing Halt Protease and Phosphatase Inhibitor Cocktail (Thermo Scientific, Waltham, $\mathrm{MA}$ ), and $200 \mu \mathrm{M}$ deferoxamine. Standardization was performed after protein concentration analysis by BCA Assay (Pierce). Samples were run in a $10 \%$ acrylamide gel and transferred at $50 \mathrm{~V}$ for 2.5 hours at $4^{\circ} \mathrm{C}$ onto nitrocellulose paper prior to blocking for 1 hour at RT in $10 \% \mathrm{milk} /$ Tris-buffered saline (TBS)/0.1\% Tween-20. Blots were then washed three times with TBS/0.1\% Tween-20 and probed with antibodies for HIF1 $\alpha$ (1:100, Santa Cruz, Dallas, TX) or VEGF (1:100, Santa Cruz) with glyceraldehyde-3-phosphate dehydrogenase (1:100, Santa Cruz) or $\beta$-tubulin (1:500, developed by M. Klymkowsky at University of Colorado, Boulder, CO, obtained from the Developmental Studies Hybridoma Bank, National Institute of Child Health and Human Development, National Institutes of Health, maintained at University of Iowa, Iowa City, IA) used as a loading control, in $10 \%$ milk/TBS/0.1\% Tween-20 (or 5\% bovine serum albumin/TBS/0.1\% Tween-20 for $\beta$-tubulin only) with overnight shaking at $4^{\circ} \mathrm{C}$. Blots continued to shake at RT for 1 hour and were then washed three times with TBS/0.1\% Tween-20 before 1-hour RT incubation with 1:3000 rabbit secondary antibody (HIF $1 \alpha$ probe, VEGF probe) (Santa Cruz) or 1:1000 mouse secondary antibody (glyceraldehyde-3-phosphate dehydrogenase probe, $\beta$-tubulin probe) (Santa Cruz). Blots were then washed three times with TBS/0.1\% Tween-20 and developed using SuperSignal West Pico Chemiluminescent Substrate (Pierce) following the manufacturer's specifications. UltraCruz Autoradiography Film (Santa Cruz) was used to make film exposures, which were then analyzed using ImageJ software (National Institutes of Health, Bethesda, MD). Protein levels were standardized using a loading control, and then normalized to the level of the standardized untreated control.

Data Analysis. Data analysis was performed using Microsoft Excel and GraphPad Prism 6 (GraphPad Software). For radioligand competition binding assays, $K_{\mathrm{i}}$ values were determined using GraphPad Prism 6 for nonlinear regression log (agonist) versus normalized response with variable slope parameters. For cell viability analysis and the fura- 2 acetoxymethyl ester calcium, ATP, NADH/NAD ${ }^{+}$, and 
CyQUANT Cell Proliferation assays, data were analyzed using Microsoft Excel. Two-tailed $t$ tests were performed where appropriate using Microsoft Excel and one-way analysis of variance was performed using GraphPad Prism 6. For one-way analysis of variance, Dunnett's post hoc test was used where appropriate for comparison with the control group. Power analysis was performed to $80 \%$ power using a power analysis calculator developed by the Department of Statistics, University of British Columbia (Vancouver, BC, Canada), based on normal distributions.

Sigma Receptor Ligands. The ligands used in this study are given in Table 1 along with their sigma receptor binding characteristics and reference citations. The synthesis of CM764 has been previously described (McCurdy et al., 2014).

\section{Results}

Radioligand Binding Competition of CM764 at Sigma-1 and Sigma-2 Receptors. The novel SN79 derivative CM764 is derived by the addition of an amine group to the fluorophenyl ring of SN79 (synthesis previously described) (McCurdy et al., 2014). The structures of both ligands are shown in Fig. 1. Competition binding was performed using $\left[{ }^{3} \mathrm{H}\right]( \pm)$-pentazocine to measure sigma-1 receptor binding and $\left[{ }^{3} \mathrm{H}\right]-1,3$-di-o-tolylguanidine in the presence of unlabeled $( \pm)$-pentazocine to measure sigma-2 receptor binding as described in Materials and Methods. Complete radioligand competition curves are shown in Fig. 2. CM764 binds sigma-2 receptors with $\sim 25$-fold selectivity over sigma-1 receptors, with $K_{\mathrm{i}}$ values of $3.5 \pm 0.9 \mathrm{nM}$ at sigma-2 receptors and $86.6 \pm$ $2.8 \mathrm{nM}$ at sigma-1 receptors. This is an increase in selectivity of 5-fold over the parent compound, $\operatorname{SN} 79\left(K_{\mathrm{i}}=7\right.$ and $27 \mathrm{nM}$ at sigma-2 and sigma-1, respectively) (Kaushal et al., 2011).
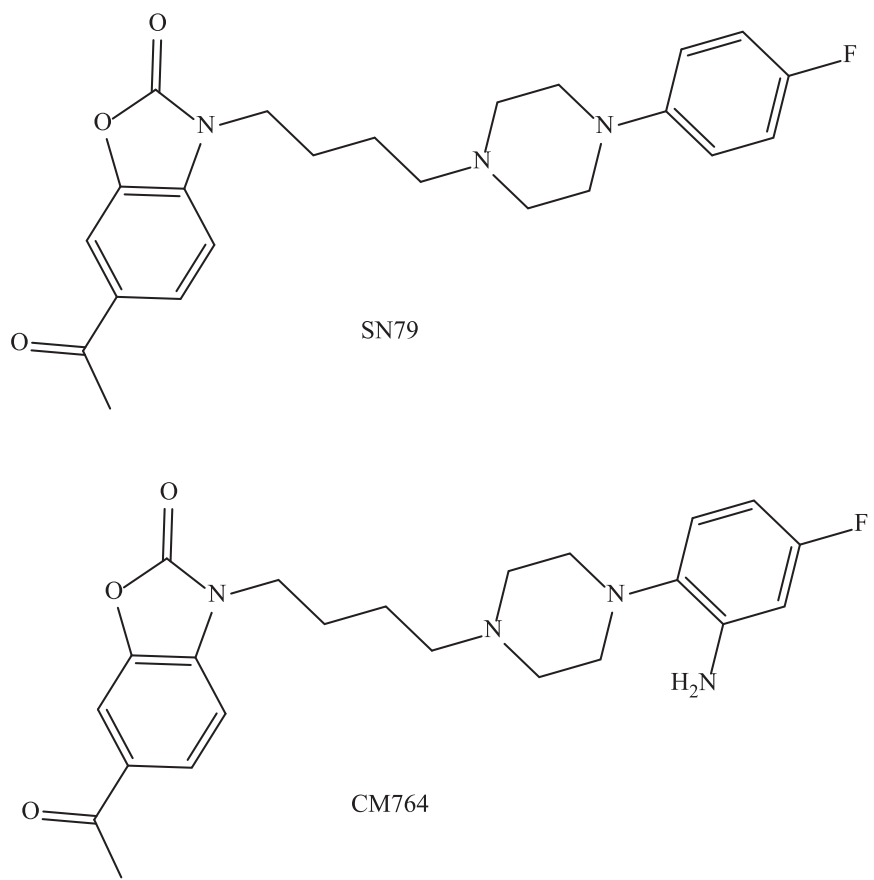

Fig. 1. Structures of SN79 and CM764. CM764 is a novel derivative of the well-characterized sigma-2 antagonist SN79. Addition of an amine to the fluorophenyl ring of SN79 results in CM764. Synthesis of CM764 was described previously (McCurdy et al., 2014). The stability of CM764 was examined using the methods described in the Supplemental Material (Supplemental Figs. 1-4). CM764 was found to be stable under the experimental conditions described herein.

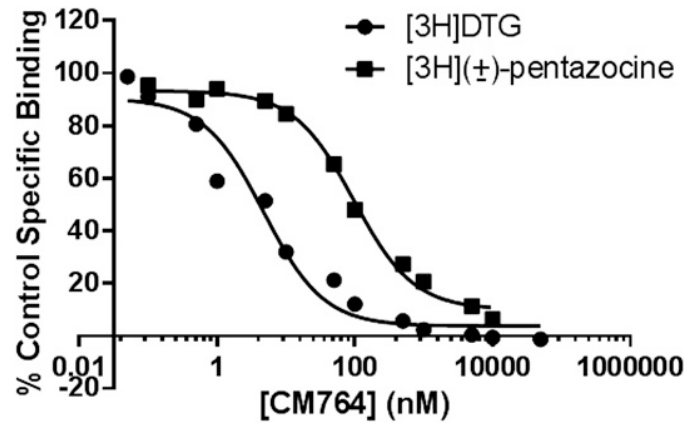

Fig. 2. CM764 binding at sigma-1 and sigma-2 receptors. Affinity of CM764 for sigma-1 and sigma-2 receptors was determined by competition binding in rat liver membranes. Assays were carried out as described in Materials and Methods, using $\left[{ }^{3} \mathrm{H}\right](+)$-pentazocine to label sigma-1 receptors and $\left[{ }^{3} \mathrm{H}\right]-1,3$-di-o-tolylguanidine $\left(\left[{ }^{3} \mathrm{H}\right] \mathrm{DTG}\right)$ in the presence of unlabeled (+)-pentazocine to label sigma-2 receptors. Results are expressed as the percentage of control specific binding at each concentration of CM764. The $K_{\mathrm{i}}$ values were determined by analysis of competition curves using GraphPad Prism 6 (GraphPad Software) and radioligand $K_{\mathrm{d}}$ values previously determined $\left(\left[{ }^{3} \mathrm{H}\right](+)\right.$-pentazocine $\left.K_{\mathrm{d}}, 7.5 \mathrm{nM} ;{ }^{3} \mathrm{H}\right] \mathrm{DTG}$ $K_{\mathrm{d}}, 17.9 \mathrm{nM}$ ) (Hellewell et al., 1994). Graphpad analysis revealed $K_{\mathrm{i}}$ values $(+$ S.D.) of $86.6 \pm 2.8$ and $3.5 \pm 0.9 \mathrm{nM}$ at the sigma- 1 and sigma-2 receptors, respectively. Each point on each curve represents the average of at least three independent experiments, with each experiment performed in duplicate.

CM764-Induced MTT Reduction in SK-N-SH Neuroblastoma. A well-established indicator of sigma-2 receptor activation is cell death. Since CM764 was found to bind sigma2 receptors well, we examined the effect of CM764 treatment on cell viability to determine the agonist or antagonist properties of the ligand. A commonly used assay to measure effects of agents on cell viability or proliferation is the MTT assay. The assay is based on the premise that reduction of the tetrazolium dye MTT to the colored formazan product, mainly in mitochondria and cytosol, is proportional to the number of viable cells. Thus, a decrease in MTT reduction usually indicates fewer cells and a cytotoxic effect, and this is the effect produced by sigma-2 receptor agonists. Human SK-NSH neuroblastoma cells highly express sigma-2 receptors and have been demonstrated to be highly sensitive to sigma-2 receptor modulators, and were thus used to determine effects of CM764 on MTT reduction (Vilner et al., 1995; Vilner and Bowen 2000; Hazelwood and Bowen 2006). The results are shown in Fig. 3. Interestingly, treatment of SK-N-SH neuroblastoma cells with CM764 induced a dose-dependent increase in MTT reduction compared with untreated control cells. This increase in MTT reduction was found to be statistically significant at 3 and $10 \mu \mathrm{M}$ doses.

Effect of CM764 Treatment on Proliferation in SK-NSH Neuroblastoma. The increase in MTT reduction that resulted from treatment of SK-N-SH neuroblastoma with CM764 could occur from two potential causes: 1) an increased number of cells available to reduce MTT compared with the untreated control condition and/or 2) some direct effect to increase the activity of the enzymes that reduce MTT in each treated cell compared with untreated cells. To determine whether the CM764-induced increase in MTT reduction was a result of increased cellular proliferation, and therefore more cells being available to reduce MTT, the CyQUANT Cell Proliferation Assay (Life Technologies) was used to measure DNA replication. Cells were treated with CM764 for up to 4 days prior to staining with CyQUANT GR dye and 


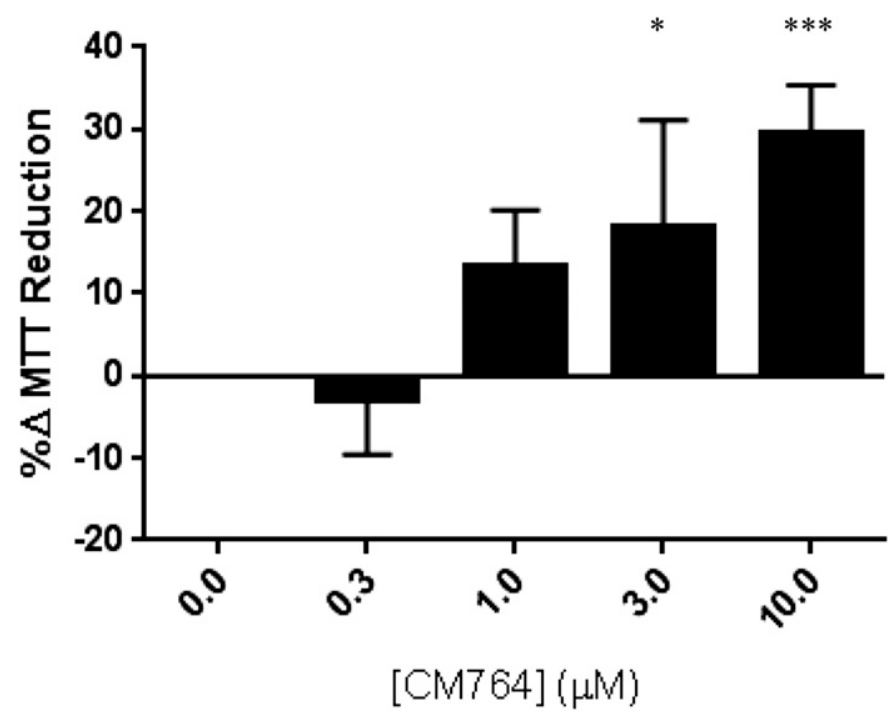

Fig. 3. Effect of CM764 treatment on MTT reduction in SK-N-SH neuroblastoma. SK-N-SH neuroblastoma cells were treated with CM764 at the indicated doses for 24 hours prior to MTT assay, carried out as described in Materials and Methods. CM764 treatment induced a statistically significant dose-dependent increase in MTT reduction (oneway analysis of variance $F=13.94$, Dunnett's post hoc comparison with control $3 \mu \mathrm{M} * P<0.05,10 \mu \mathrm{M} * * * P<0.001)$. Results are expressed as an average percent change in MTT reduction \pm S.D. in treated samples relative to an untreated control for at least three independent experiments, with each experiment having five replicates per condition.

quantification as described in Materials and Methods. Results are shown in Fig. 4. There was no significant difference in DNA replication observed at any time point up to 4 days between cells treated with $10 \mu \mathrm{M}$ CM764 and untreated control cells. In addition, these results were confirmed by counting DAPI [4',6-diamidino-2-phenylindole]-stained cells, which showed no significant differences between treated and control groups (data not shown). These data indicate that treatment of SK-N-SH neuroblastoma cells with $10 \mu \mathrm{M}$ CM764 does not result in increased DNA replication or cellular proliferation above that of normal cell turnover and proliferation. The results further show that treatment of longer than 24 hours, up to 4 days, had no toxic effect on the cells. Thus, the increased reduction of MTT observed in CM764-treated cells could be attributed to stimulated reductive metabolism without a concurrent stimulation of cell division.

Pharmacological Characterization of CM764Induced MTT Reduction. The stimulative effect demonstrated by CM764 treatment of SK-N-SH neuroblastoma cells has yet to be reported as a result of sigma-2 receptor activation, which has previously only been associated with a decrease in cell viability (agonist activity). To determine whether the stimulation of MTT reduction induced by CM764 treatment is mediated by the sigma-2 receptor, several sigma-2 receptor modulators were investigated in combination with CM764 treatment to determine if the effect could be attenuated. The effects of known sigma receptor antagonists are shown in Fig. 5. CM764 and each antagonist were dosed simultaneously and MTT reduction was measured after 24-hour treatment. All sigma-2 receptor antagonists examined were able to significantly attenuate the stimulation of MTT reduction induced by CM764 alone, without inducing a significant effect on MTT reduction when used alone. The

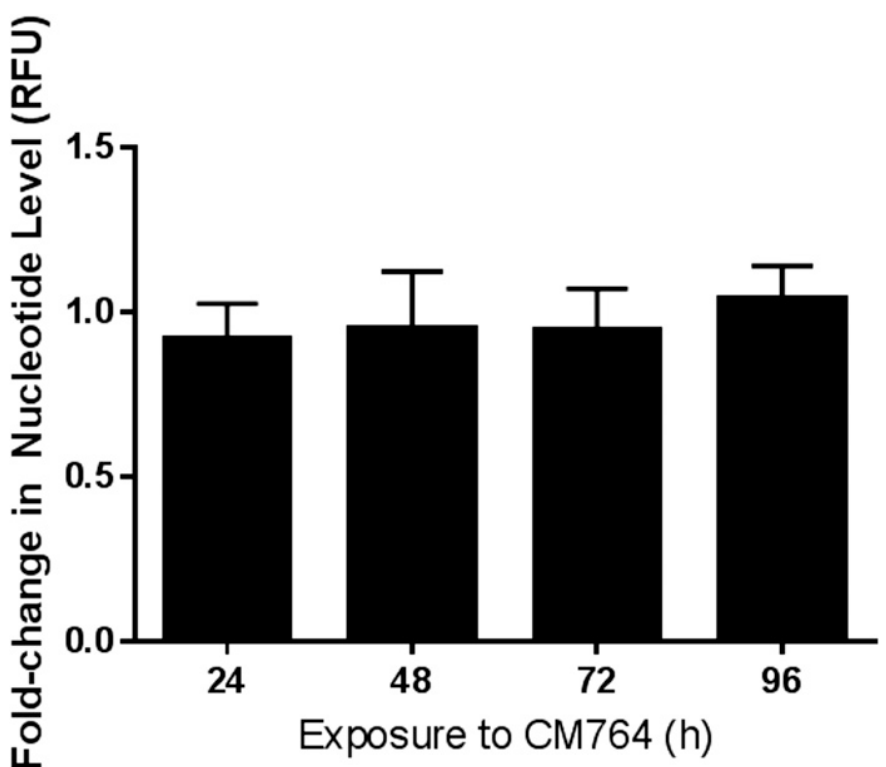

Fig. 4. Effect of CM764 treatment on DNA replication in SK-N-SH neuroblastoma. DNA replication was measured to determine the effect of CM764 treatment on cellular proliferation using the CyQUANT assay (Life Technologies) as described in Materials and Methods. There was no significant change in DNA synthesis as measured by CyQUANT GR dye fluorescence in cells treated with CM764 compared with untreated cells up to 96 -hour exposure. This indicates that the effect of CM764 on SK-N-SH neuroblastoma does not result in an increase in cellular proliferation. Results are presented as the fold change in level of nucleotides as measured by the ratio of relative fluorescence units (RFU) in treated and untreated cells at that time point. Data presented are the average of two independent experiments \pm S.D., with each experiment having five replicates per condition. Media and ligand were changed after every 24-hour period.

well-characterized sigma-2 receptor antagonist SN79, the parent compound for CM764, was able to completely eliminate the stimulation induced by CM764 alone. A 24-hour treatment of $30 \mu \mathrm{M}$ SN79 alone had no significant effect on MTT reduction in SK-N-SH neuroblastoma compared with an untreated control. Similarly, $0.3 \mu \mathrm{M}$ CM572, a sigma-2 receptor partial agonist $\left(K_{\mathrm{i}}=15 \mathrm{nM}\right.$ at sigma-2 receptors and $K_{\mathrm{i}} \geq 10 \mu \mathrm{M}$ at sigma-1 receptors), which we have previously shown has antagonist properties at this concentration in SKN-SH neuroblastoma (Nicholson et al., 2015), eliminated CM764-induced MTT hyper-reduction when dosed in combination with $10 \mu \mathrm{M}$ CM764. The sigma-1/sigma-2 antagonists BD1047 [N'-[2-(3,4-dichlorophenyl)ethyl]-N,N,N'-trimethylethane1,2-diamine] $\left(K_{\mathrm{i}}=47 \mathrm{nM}\right.$ at sigma-2 receptors and $K_{\mathrm{i}}=0.93$ $\mathrm{nM}$ at sigma-1 receptors) (Matsumoto et al., 1995) and BD1063 [1-2-(3,4-dichlorophenyl)ethyl-4-methylpiperazine] $\left(K_{\mathrm{i}}=449 \mathrm{nM}\right.$ at sigma-2 receptors and $K_{\mathrm{i}}=9.15 \mathrm{nM}$ at sigma- 1 receptors) (Matsumoto et al., 1995) were both able to eliminate the increase in MTT reduction induced by CM764 treatment alone. NE100 [4-methoxy-3-(2-phenylethoxy)-N,N-dipropylbenzeneethanamine], which has selectivity for the sigma-1 receptor yet still has measurable affinity for the sigma-2 receptor $\left(K_{\mathrm{i}}=84.7 \mathrm{nM}\right.$ at sigma-2 receptors and $K_{\mathrm{i}}=1.54 \mathrm{nM}$ at sigma-1 receptors) (Chaki et al., 1994) was able to significantly attenuate but not completely eliminate the signal produced by CM764 when it was dosed in combination at $1 \mu \mathrm{M}$. The ability of these sigma-2 receptor modulators to attenuate or entirely eliminate the CM764-induced increase in MTT reduction in SK-N-SH neuroblastoma indicates that this effect is 


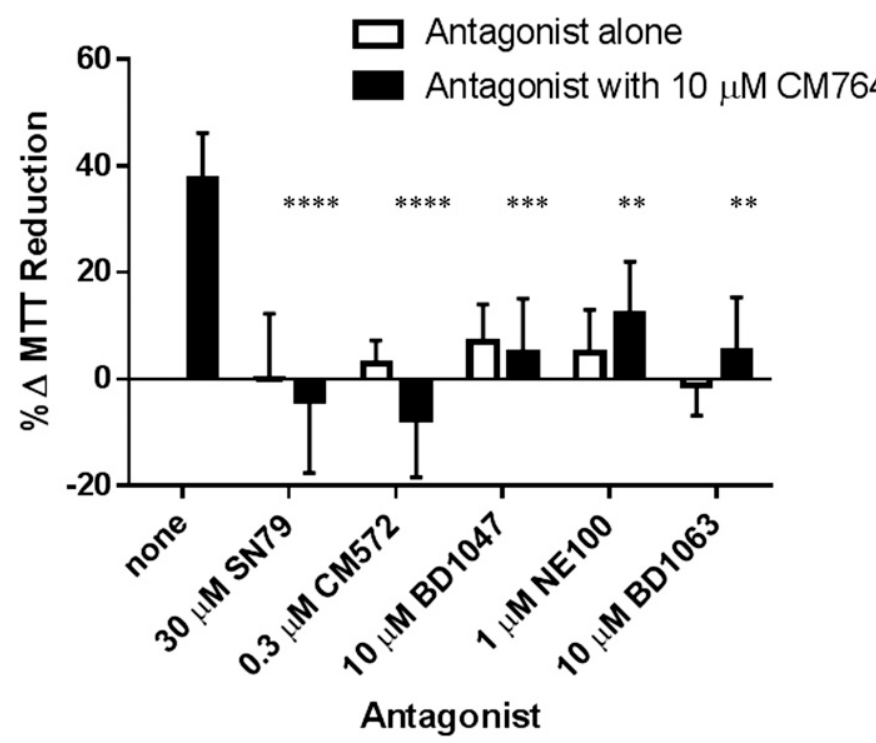

Fig. 5. Effect of sigma-2 receptor antagonists on CM764-induced MTT reduction in SK-N-SH neuroblastoma. Cells were exposed to $10 \mu \mathrm{M}$ CM764 alone, the indicated antagonist alone, or to the combination of $10 \mu \mathrm{M} \mathrm{CM} 764$ and antagonist for 24 hours. MTT reduction was measured as described in Materials and Methods. No antagonist alone produced a significant effect on MTT reduction compared with an untreated control. All antagonists were able to significantly attenuate the stimulative effect of CM764 on MTT reduction (one-way analysis of variance $F=13.73$ ). CM572 and SN79, the most highly sigma-2 selective antagonists investigated, were both able to fully attenuate CM764-induced increase in MTT reduction (Dunnett's test for multiple comparisons compared with an untreated control, $* * * * P<0.0001$ ). The other sigma-2 antagonists, although more selective for sigma-1 receptors, were also able to significantly attenuate CM764-induced MTT reduction. BD1047: ***P $<$ 0.001; NE100: $* * P<0.01$; BD1063: $* * P<0.01]$. The data support the notion that the effect is sigma-2 receptor mediated. Results are presented as an average increase in MTT reduction compared with an untreated control for at least three independent experiments, with each experiment performed with five replicates per condition.

sigma-2 mediated and represents a novel function for this receptor.

CM764 does exhibit significant affinity for the sigma-1 receptor, although it is a sigma-2-selective ligand. Some of the ligands investigated for antagonist activity against CM764 are selective for the sigma-1 receptor, although doses used in these experiments were all at least 200-fold greater than the sigma- 2 receptor $K_{\mathrm{i}}$ of the ligands, and therefore could be expected to be acting at the sigma- 2 receptor as well as the sigma-1 receptor. In light of this, it was necessary to examine whether the stimulation of MTT reduction observed in SK-N-SH neuroblastoma in response to treatment with CM764 could be a result of sigma-1 receptor activation either exclusively or in addition to sigma-2 receptor activation. To test this, the effect of treatment with the sigma-1 agonist (+)-pentazocine $\left(K_{\mathrm{i}}=1,542 \mathrm{nM}\right.$ at sigma- 2 receptors and $K_{\mathrm{d}}=$ $7.5 \mathrm{nM}$ at sigma-1 receptors) (Hellewell et al., 1994) was examined in SK-N-SH cells. (+)-Pentazocine was unable to induce any significant change in MTT reduction compared with untreated control cells up to $1 \mu \mathrm{M}$, which is over 130 -fold above its sigma-1 receptor $K_{\mathrm{i}}$ value (the experiment was repeated twice with similar results, with five replicates per condition in each experiment). Additionally, CM572 was able to completely attenuate the effect of CM764 on MTT reduction, although CM572 exhibits no significant binding at the sigma-1 receptor. This antagonism demonstrates

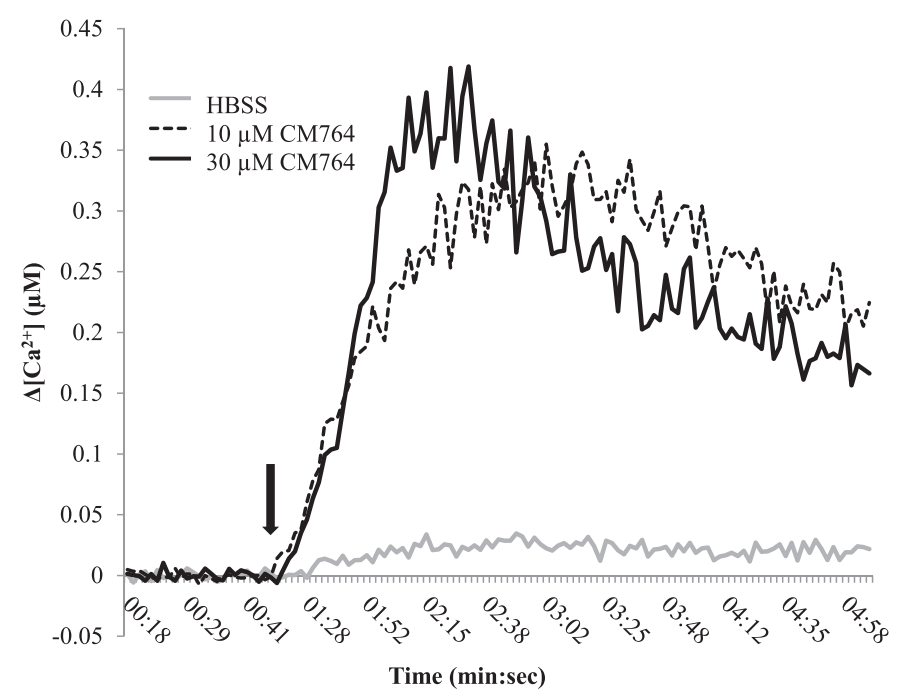

Fig. 6. Effect of CM764 treatment on intracellular calcium in SK-N-SH neuroblastoma. Cells were loaded with fura-2 acetoxymethyl ester for 60 minutes prior to CM764 or vehicle injection (injection indicated by the black arrow). CM764 injection induced an immediate increase in cytosolic calcium in SK-N-SH neuroblastoma, as has been previously demonstrated in response to sigma-2 receptor activation. A representative trace for each condition is shown. Data are presented as a change in intracellular calcium level with the baseline removed, with the baseline level of calcium determined by the average of 25 ratio measurements prior to injection. The experiment was repeated four times with similar results, with each experiment having four replicates per condition.

that the stimulation of MTT reduction induced by CM764 treatment could be entirely eliminated by selectively blocking the sigma-2 receptor, without blocking the sigma-1 receptor at all. These data confirm that this effect is sigma-2 receptor mediated and does not involve sigma-1 receptors.

Effect of CM764 Treatment on Intracellular Calcium. A common characteristic of sigma-2 receptor activation is an immediate, transient increase in intracellular calcium. However, this calcium response has not been consistently coupled to apoptosis. Therefore, we examined whether CM764 would induce this nontoxic calcium transient, commonly resultant from sigma-2 receptor activation. Using fura-2 acetoxymethyl ester ratiometric dye, we determined that injection of CM764 for final concentrations of 10 and $30 \mu \mathrm{M}$ both induced a robust, immediate calcium transient, with the calcium level decreasing toward baseline within the 5-minute recording (Fig. 6). The higher dose of CM764 reached a slightly greater peak increase in calcium level, and within a faster time frame than the lower dose. These data indicate that CM764 is able to induce the immediate calcium transient characteristic of sigma-2 receptor activation, and confirm that this signal can occur independently from the induction of apoptosis.

Effect of CM764 on $\mathrm{NAD}^{+} / \mathrm{NADH}_{\text {Levels. Since MTT }}$ dye is reduced to formazan by cellular reductase enzymes that are mainly found in mitochondria and cytosol (although they are also present in lysosomes and endosomes) (Liu et al., 1997), these data suggest that CM764 treatment stimulates these enzymes to increase their activity. Several oxidoreductase enzymes responsible for the reduction of MTT into formazan are known to be NADH dependent (Berridge et al., 2005). Therefore, we tested whether the increase in MTT reduction exhibited in SK-N-SH cells upon treatment with CM764 could be reflected in an increase in levels of this 


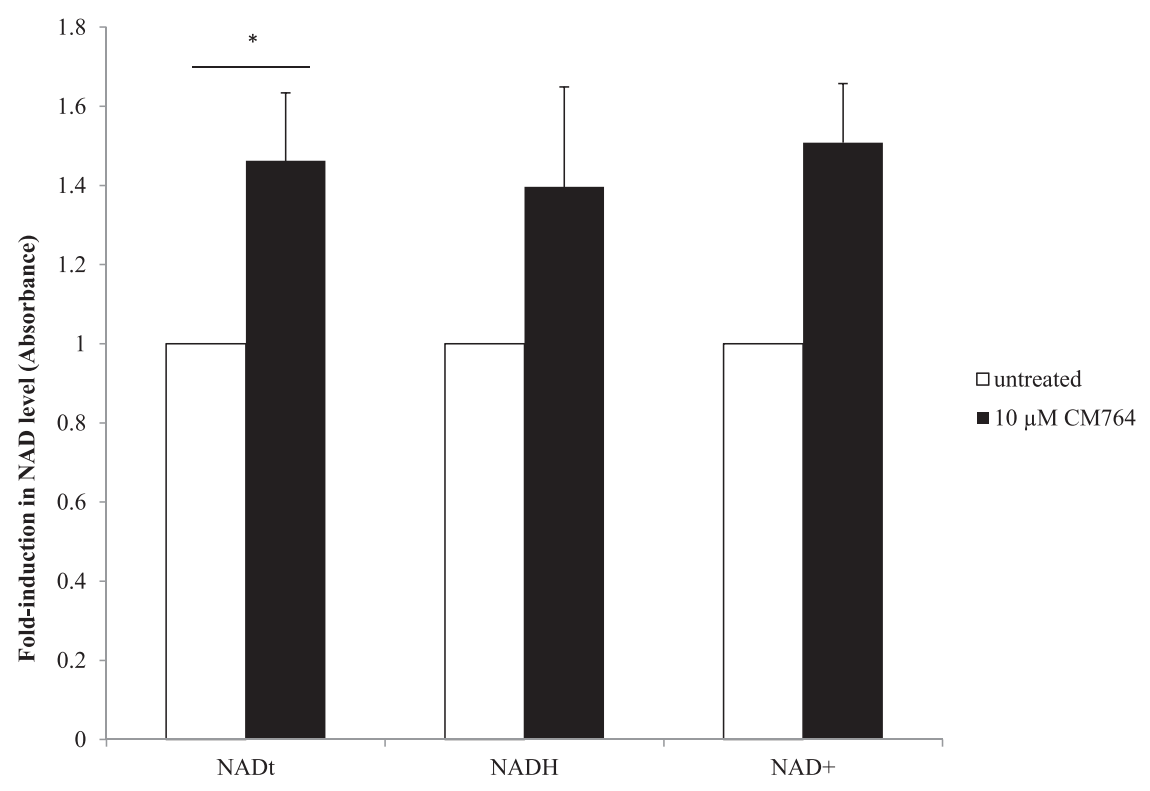

Fig. 7. Changes in $\mathrm{NADH} / \mathrm{NAD}^{+}$in response to CM764 exposure. Cells were exposed to $10 \mu \mathrm{M}$ CM764 for 24 hours prior to NADH/NAD ${ }^{+}$assay, carried out as described in Materials and Methods. Treatment with CM764 induced a statistically significant, yet not robust $\sim 1.4$-fold increase in total $\mathrm{NAD}\left(\mathrm{NADH}+\mathrm{NAD}^{+}\right)$compared with an untreated control [Student's $t$ test, $P<0.05(P=0.043)$ ]. NADH and $\mathrm{NAD}^{+}$levels each showed a similar trend to total $\mathrm{NAD}$, but did not reach statistical significance. Results are presented as an average fold increase in absorbance in treated wells compared with an untreated control for three independent experiments \pm S.D., with each experiment being performed in triplicate.

cofactor, which could facilitate enzyme activity. Using a colorimetric kit for quantification of $\mathrm{NAD}^{+} / \mathrm{NADH}$ levels, we were able to determine that there was a statistically significant increase in total NAD (the sum of NADH and $\mathrm{NAD}^{+}$) in cells treated with $10 \mu \mathrm{M}$ CM764 for 24 hours compared with untreated cells. The results are shown in Fig. 7. For both $\mathrm{NAD}^{+}$individually and NADH individually neither measurement reached a statistically significant change from untreated cells. This appears to be due to variability between which reduction state increased more than the other since $\mathrm{NAD}^{+}$ levels were determined indirectly as the difference between $\mathrm{NAD}$ total and NADH, which were both measured directly. Therefore, the variability in $\mathrm{NAD}^{+}$levels was dependent on the variability in $\mathrm{NADH}$ measurements, which did not allow for significance in $\mathrm{NAD}^{+}$unless significance was reached for $\mathrm{NADH}$. However, the overall increase in total NAD in CM764treated cells compared with untreated cells demonstrates that increased levels of the cofactor required for enzymatic reduction of MTT was indeed induced by CM764. This is likely a contributing factor to the observed increase in MTT reduction in CM764-treated cells, perhaps in addition to direct stimulation of oxidoreductase enzymes.

Effect of CM764 Treatment on ATP Levels. The increase in NADt and reduction of MTT that were induced by CM764 treatment of SK-N-SH neuroblastoma cells indicate an overall increase in metabolic function. To test this hypothesis, we measured ATP levels in CM764-treated cells compared with untreated cells using a fluorescent kit as described in Materials and Methods. The results are shown in Fig. 8. Cells treated for 24 hours with $10 \mu \mathrm{M}$ CM764 showed a modest yet statistically significant increase in ATP with average ATP levels being $13 \%$ higher in treated cells compared with untreated cells (range of $8 \%-23 \%$ ). These data suggest that CM764 treatment does indeed stimulate metabolism, perhaps through induction of glycolysis rather than the tricarboxylic acid (TCA) cycle. TCA cycle stimulation would be expected to create a more significant increase in ATP compared with the addition of glycolysis, which would produce only a modest increase in ATP production.
CM764-Induced Production of ROS. Under glycolysis cells produce pyruvate, which can act as an antioxidant. Furthermore, if some ATP production that results from oxidative phosphorylation in untreated cells was indeed a result of glycolysis in CM764-treated cells as hypothesized previously, then we would expect to see a decrease in ROS generated from oxygen consumption in oxidative phosphorylation. To determine whether this effect could result from

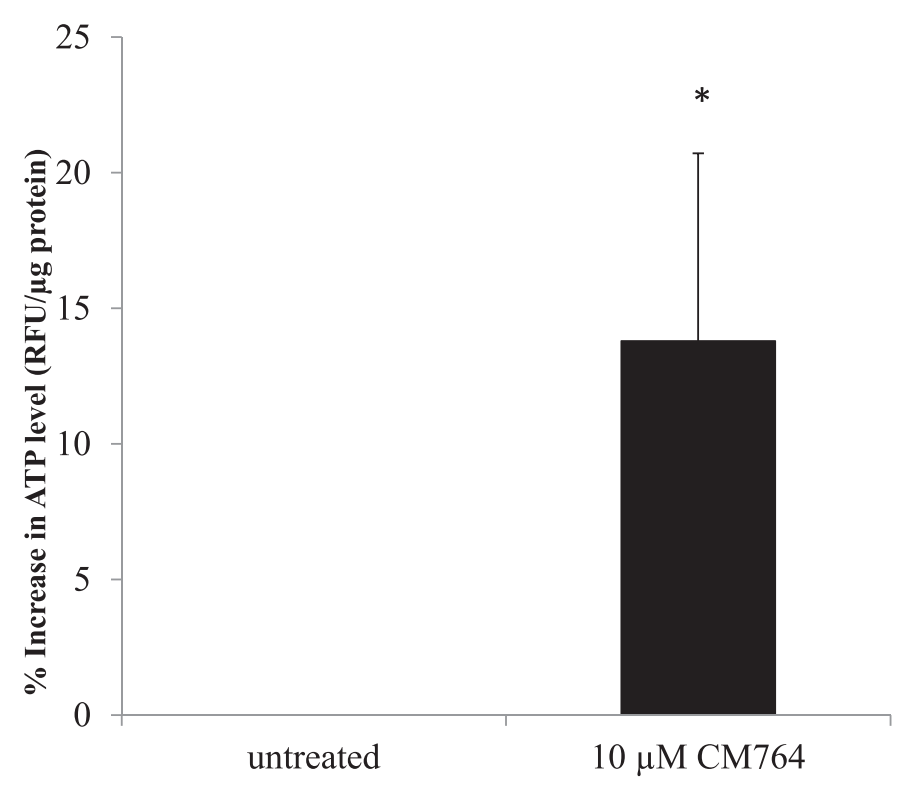

Fig. 8. Changes in ATP levels in response to CM764 exposure. Cells were exposed to $10 \mu \mathrm{M} \mathrm{CM} 764$ for 24 hours prior to ATP assay as described in Materials and Methods. Treatment with CM764 induced an $\sim 13 \%$ increase in ATP level compared with an untreated control [Student's $t$ test, ${ }^{*} P<0.05(P=0.032)$ ]. Results are presented as an average percent change in ATP levels as determined by an increase in relative fluorescence normalized to protein concentration in treated cells compared with an untreated control for three independent experiments and controlled for cell number in one experiment for a total of four independent experiments \pm S.D., with each experiment being performed in duplicate. 

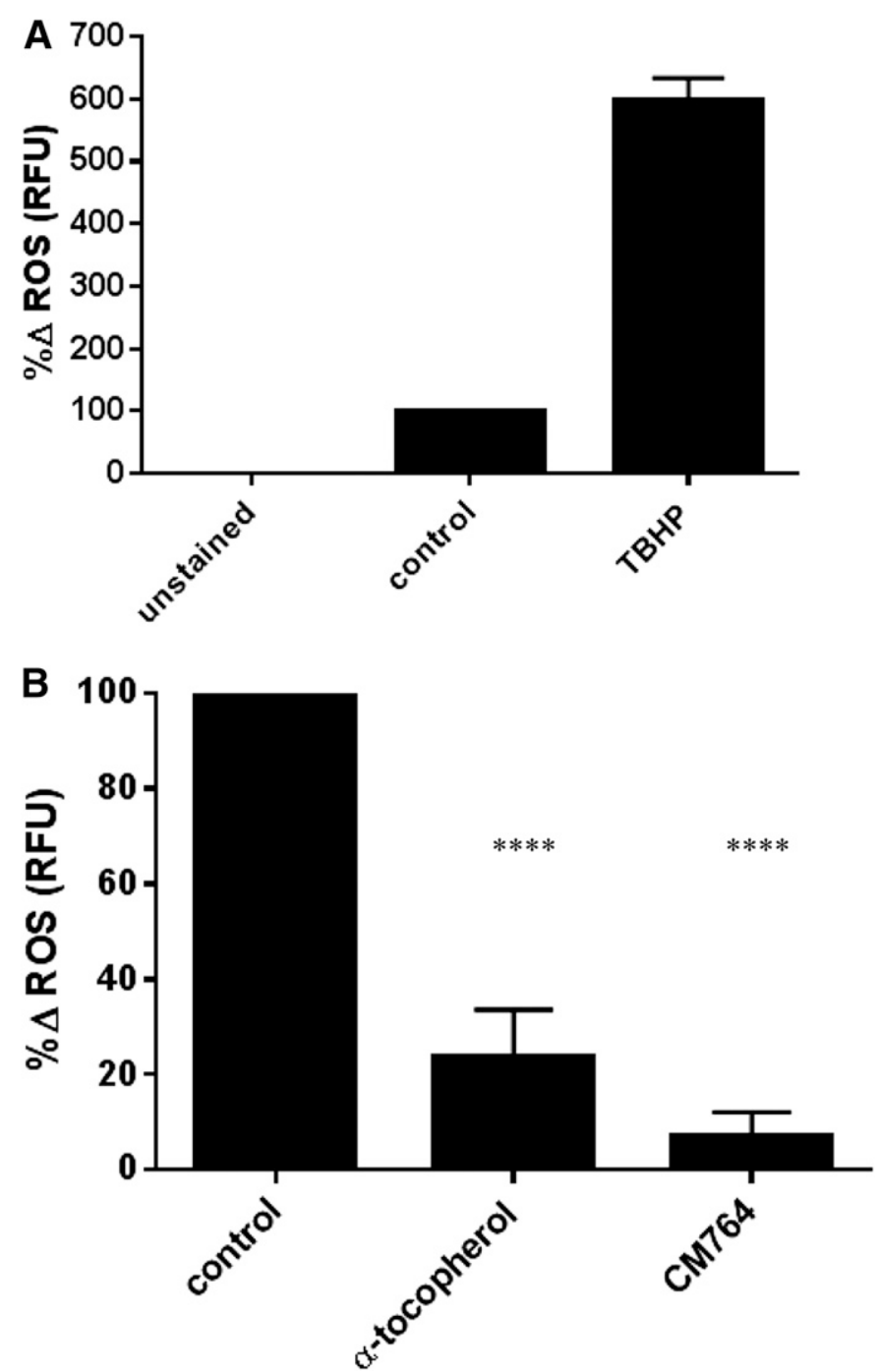

Fig. 9. Effect of CM764 on ROS levels in SK-N-SH neuroblastoma cells. Cells were stained with DCFDA prior to treatment with $10 \mu \mathrm{M} \mathrm{CM} 764$ for 4 hours, followed by fluorescence measurement as described in Materials and Methods. The effectiveness of the assay, showing the effect of $500 \mu \mathrm{M}$ tert-butyl hydrogen peroxide (TBHP) as a positive control for the production of ROS is demonstrated in (A). The results of treatment with the antioxidant $\alpha$-tocopherol (vitamin E, $200 \mu \mathrm{g} / \mathrm{ml}$ ) and treatment with $10 \mu \mathrm{M}$ CM764 are shown in (B). Treatment of SK-N-SH neuroblastoma cells with CM764 resulted in a marked decrease in ROS that was more effective than that of $\alpha$-tocopherol (95\% and 76\%, respectively). Results were highly significant (one-way analysis of variance $F=238.4$, Dunnett's test for multiple comparisons compared with the untreated control; $* * * * P<0.0001$ for $\alpha$-tocopherol, $* * * * P<0.0001$ for CM764). Results are presented as an average of the percent change in ROS levels achieved \pm S.D. compared with an untreated control normalized to $100 \%$ for three independent experiments, each experiment having four replicates per condition.

CM764 treatment, we measured ROS accumulation using the ROS-sensitive DCFDA dye. Cells were stained with DCFDA and then treated with $10 \mu \mathrm{M}$ CM764 for 4 hours prior to measurement of fluorescence as described in Materials and Methods. The results are shown in Fig. 9. To ensure effectiveness of the assay, tert-butyl hydrogen peroxide was used as a positive control (Fig. 9A) compared with untreated DCFDAstained cells, which were normalized to $100 \%$ relative fluorescence units. Basal fluorescence of unstained cells was subtracted from each measurement. As a negative control, treatment of SK-N-SH neuroblastoma with the antioxidant $\alpha$-tocopherol (vitamin E) showed a decrease in ROS of $76 \%$ compared with an untreated control. Treatment with $10 \mu \mathrm{M}$ CM764 for just 4 hours showed a decrease in ROS of $95 \%$ compared with an untreated control. These data indicate a very significant decrease in ROS in response to treatment with CM764, indicating a strong antioxidant effect resultant from activation of the sigma-2 receptor through this mechanism. This may be due to induction of glycolysis, which could explain the antioxidant effect of CM764 treatment.

To determine whether the reduction in ROS induced by treatment with CM764 was a result of direct radical scavenging, as with $\alpha$-tocopherol, the experiment was repeated using $10 \mu \mathrm{M}$ CM572. CM572 is a close structural analog of CM764, lacking the amine group on the fluorophenyl ring and instead having an isothiocyanate moiety on the heterocyclic ring system. A $10 \mu \mathrm{M}$ dose of CM572 did not induce an increase in MTT reduction compared with control cells, and also did not result in any significant change in level of ROS compared with untreated cells even after 6 hours of treatment (the experiment was performed using four replicates per condition; data not shown). Thus, the effect of CM764 on ROS is due to a signaling mechanism and not to direct radical scavenging.

Effect of CM764 on HIF1 $\alpha$ Protein Levels. A hallmark of cells undergoing glycolysis under normoxic conditions (aerobic glycolysis) is the expression of HIF $1 \alpha$. A link between treatment of tumor cells with the sigma modulator rimcazole and increased expression of HIF $1 \alpha$ has been established previously (Achison et al., 2007). Therefore, we decided to investigate whether this transiently expressed protein might be stabilized or increasingly translated upon treatment with CM764. Cell lysates of SK-N-SH neuroblastoma were made after treatment with $10 \mu \mathrm{M}$ CM764 for the indicated length of time and were used to western blot for the presence of HIF $1 \alpha$ as described in Materials and Methods. A representative blot of HIF $1 \alpha$ and loading control GADPH are shown in Fig. 10A and quantified in Fig. 10B. Our results indicate a strong induction of $\operatorname{HIF} 1 \alpha$, either by stabilization of the translated protein or by increased translation of mRNA, in response to treatment with CM764. Increased expression was most significant after 24 hours, showing $>14$-fold induction. However, expression was already $>4$-fold increased after only 6 hours of treatment. The observed induction of the HIF $1 \alpha$ protein level is consistent with previous data that show increased expression of HIF $1 \alpha$ in cells that preferentially employ glycolysis under conditions of normoxia (Dery et al., 2005; Kuschel et al., 2012). These data suggest that CM764 treatment does induce aerobic glycolysis in SK-N-SH neuroblastoma cells, consistent with our results from ROS and ATP studies described previously.

Effect of CM764 on VEGF Protein Levels. To confirm the activity of increased HIF $1 \alpha$ protein levels in SK-N-SH neuroblastoma cells in response to treatment with $10 \mu \mathrm{M}$ CM764, a transcriptional target of HIF $1 \alpha$ was measured in response to the same treatment. VEGF has been extensively described as a target of $\mathrm{HIF} 1 \alpha$ transcriptional regulation, and anti-VEGF therapy has been shown to impair ATP levels (Curtarello et al., 2015). Therefore, we examined the effect of CM764 treatment on VEGF expression in SK-N-SH neuroblastoma. The results are shown in Fig. 11A and quantified in Fig. 11B. Our results confirm that the protein level of VEGF is increased by over 4 -fold in cells treated with $10 \mu \mathrm{M}$ CM764 

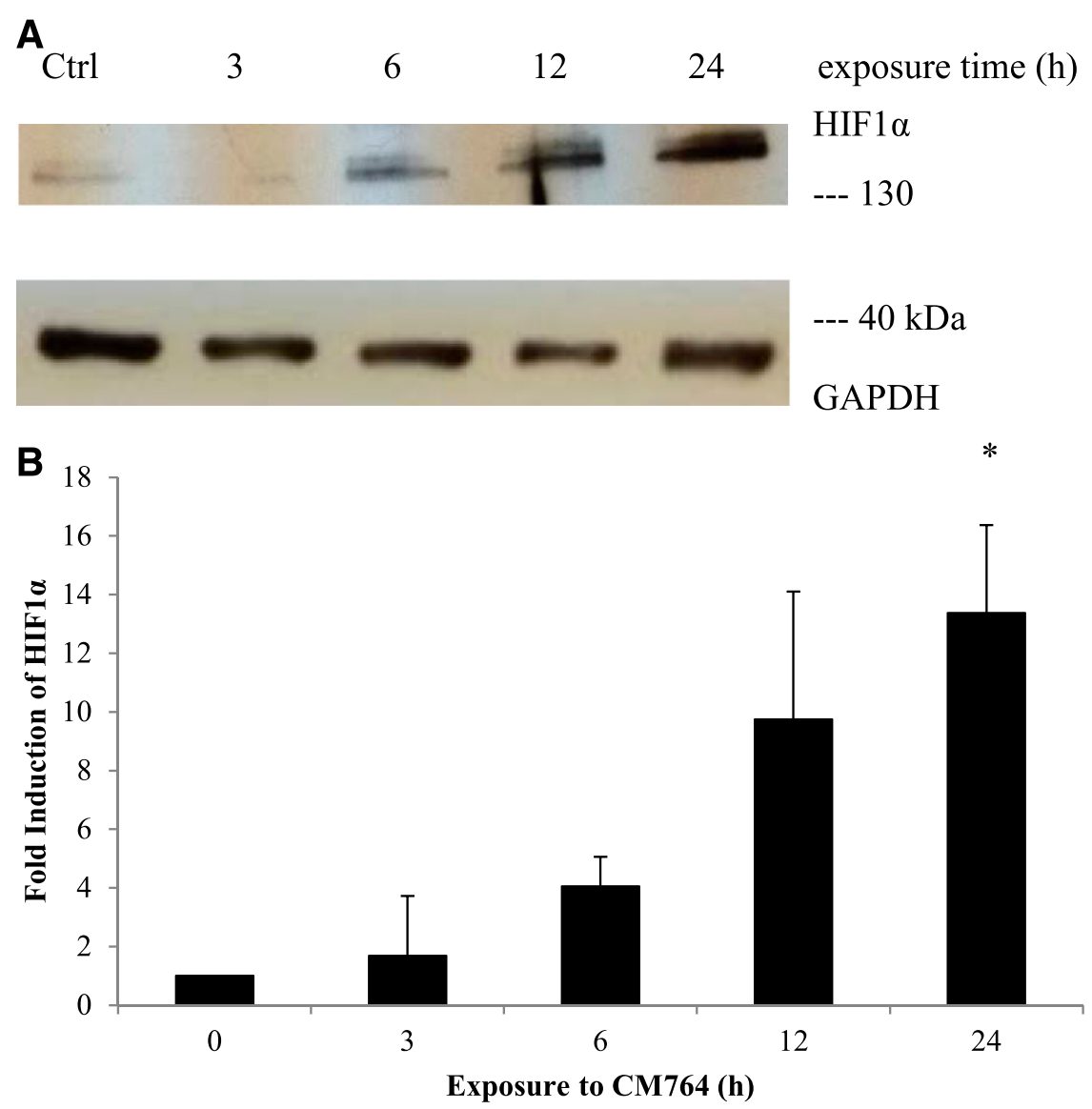

Fig. 10. Effect of CM764 treatment on levels of HIF $1 \alpha$ in SK-N-SH neuroblastoma. Cell lysates of SK-N-SH neuroblastoma cells were made after treatment with $10 \mu \mathrm{M}$ CM764 for the indicated amount of time and were used for western blotting for HIF $1 \alpha$ as described in Materials and Methods. (A) HIF $1 \alpha$ western blot and glyceraldehyde-3-phosphate dehydrogenase (GAPDH) loading control. (B) Independent blots were quantified and the ratio of HIF $1 \alpha /$ GAPDH determined and averaged for all experiments. Data are expressed as fold increase in ratio relative to control treated without CM764. Treatment with CM764 resulted in an increase in HIF $1 \alpha$ level as early as 6 hours after exposure (oneway analysis of variance $F=8.716$, Dunnett's test for multiple comparisons compared with untreated control $* P<0.05)$. Results are an average of two independent experiments. A representative blot is shown. compared with untreated cells. This increased expression was most significant after 24 hours of treatment, lagging behind the observed increased expression of HIF $1 \alpha$, which presumably regulated the VEGF transcription.

Effect of CM764 across Multiple Cell Types. To determine whether the increase in MTT reduction induced by CM764 treatment is exclusive to SK-N-SH neuroblastoma, the effect of this treatment was investigated in multiple cell lines. Human embryonic kidney (HEK293 T/17) cells and human osteosarcoma (MG-63) cells were treated with CM764 at the indicated doses for 24 hours prior to MTT assay. The results are shown in Fig. 12. The maximal stimulation achieved with $10 \mu \mathrm{M}$ CM764 in SK-N-SH neuroblastoma after 24 hours of treatment was matched using the same treatment in HEK293 T/17 cells and MG-63 cells. These data demonstrate that the increased reduction of MTT induced by CM764 activity at sigma-2 receptors is not exclusive to one cell type but rather may be present across a variety of cell types. Additionally, this effect is not exclusive to cancerous cell lines since it is also effective in noncancerous HEK cells, although there may be a slight trend toward less activity in the HEK cells compared with SK-N-SH and MG-63 cells at the lower concentrations. Together, these data suggest a role for sigma- 2 receptors outside of cytotoxicity in cancer cells.

\section{Discussion}

Here, we demonstrate a previously unreported metabolic regulatory role of sigma-2 receptors. CM764 binds sigma-2 receptors with high affinity $\left(K_{\mathrm{i}}=3.5 \mathrm{nM}\right)$ and 25-fold selectivity over sigma-1 receptors (Fig. 2), a significant increase in selectivity over the parent compound SN79. Since sigma-2 receptor activation has traditionally been associated with a reduction in cell viability, we used the MTT assay to measure potential loss of cell viability in response to CM764 exposure. Interestingly, treatment of SK-N-SH neuroblastoma cells with CM764 resulted in a significant increase in MTT reduction compared with untreated cells (Fig. 3). This could result from cellular proliferation, stimulation of oxidoreductase activity, or both. Results from CyQUANT cell proliferation assays indicated no change in proliferation or DNA replication in response to treatment with CM764, suggesting a strictly metabolic effect (Fig. 4).

This stimulative effect on MTT reduction could be attenuated by sigma-2 receptor antagonists with and without measurable affinity at sigma-1 receptors, but this could not be replicated by sigma-1 receptor activation by the sigma-1selective agonist (+)-pentazocine. All sigma-2 receptor modulators investigated attenuated CM764-induced stimulation of MTT reduction, while no effect on MTT reduction was observed for each antagonist independently (Fig. 5). Specifically of note is the attenuation of the CM764-induced increase in MTT reduction by antagonism with CM572, which has high affinity for the sigma-2 receptor $\left(K_{\mathrm{i}}=15 \mathrm{nM}\right)$ but no significant affinity for the sigma- 1 receptor $\left(K_{\mathrm{i}} \geq 10,000 \mathrm{nM}\right)$. These data indicate that this is a novel sigma-2-mediated effect that is independent of sigma-1 receptor activation.

CM764 injection onto fura-2-loaded SK-N-SH neuroblastoma cells induced an immediate, robust, transient calcium response, consistent with previous reports of sigma- 2 receptor 

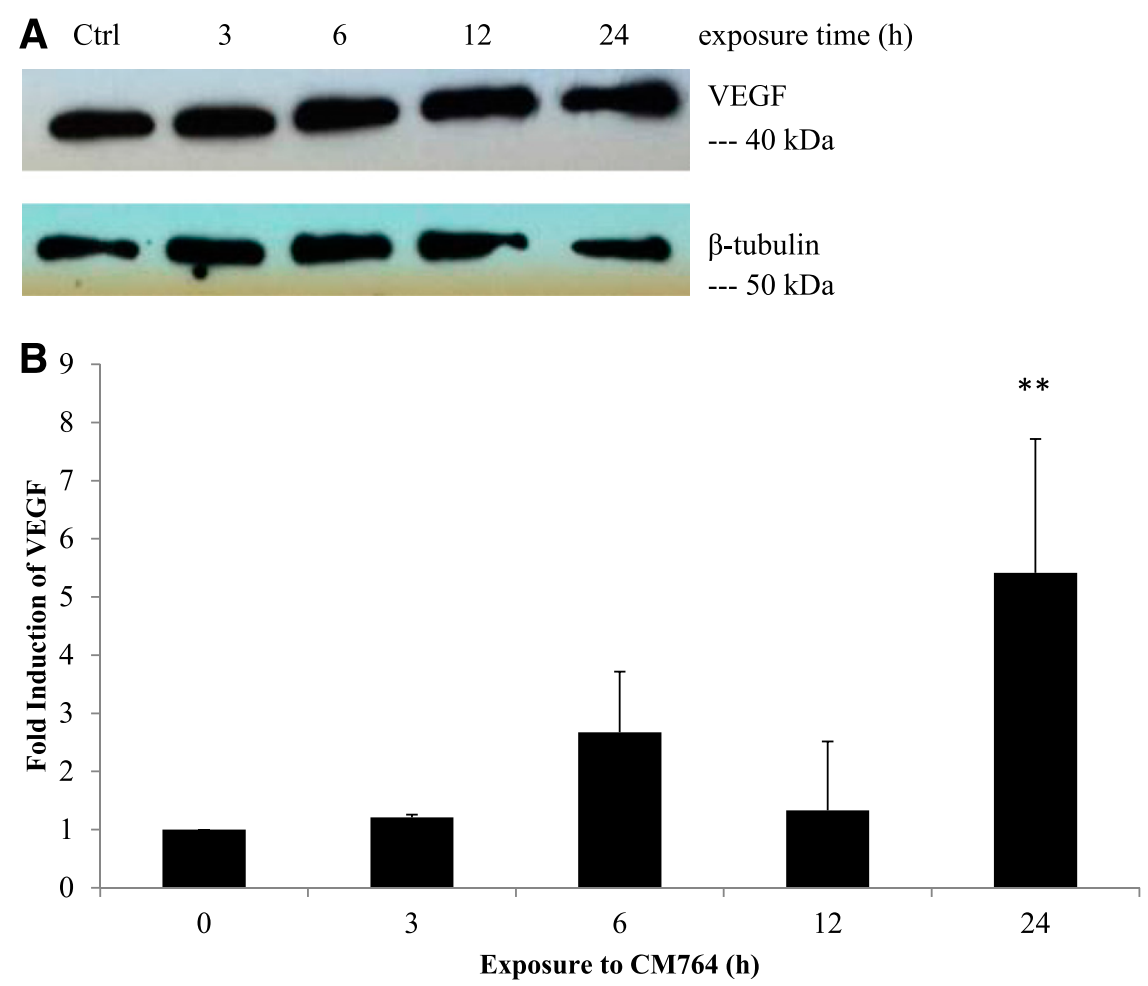

Fig. 11. Effect of CM764 treatment on expression of VEGF in SK-N-SH neuroblastoma. Cell lysates of SK-N-SH neuroblastoma cells were made after

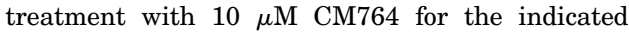
amount of time and were used for western blotting for VEGF as described in Materials and Methods. (A) VEGF western blot and $\beta$-tubulin loading control. (B) Independent blots were quantified and the ratio of the VEGF/loading control ( $\beta$-tubulin or glyceraldehyde-3-phosphate dehydrogenase) was determined and averaged for all experiments. Data are expressed as fold increase in ratio relative to control treated without CM764. Treatment with CM764 induced protein expression of VEGF after 24-hour exposure, following an earlier increase in HIF $1 \alpha$ expression as shown in Fig. 10 (one-way analysis of variance $F=$ 6.558, Dunnett's test for multiple comparisons compared with untreated control $* * P<0.01)$. Results shown are an average of three independent experiments. A representative blot is shown. activation (Fig. 6). This observation lends further support to the action of CM764 at sigma-2 receptors, as well as confirms that this calcium response can be uncoupled from induction of apoptosis. Since changes in calcium level are also known to be early steps in several important metabolic pathways, these data are also consistent with a metabolic effect resultant from sigma-2 receptor activation by CM764.

Since reduction of MTT is known to be NADH dependent, $\mathrm{NADH} / \mathrm{NAD}^{+}$levels were investigated in response to CM764 treatment. CM764 treatment induced an increase in total $\mathrm{NAD}\left(\mathrm{NADH}+\mathrm{NAD}^{+}\right)$compared with untreated cells, indicating that levels of this cofactor are increased as a result of sigma-2 receptor activation by CM764 (Fig. 7). However, the increase was modest, and while likely not limiting, the increase in NADH induced by CM764 activation of sigma-2 receptors is unlikely to be the driving factor for the observed increase in MTT reduction. The increase in NADt observed in response to CM764 treatment indicated moderate stimulation of a metabolic pathway, perhaps less efficient than an overall stimulation of oxidative phosphorylation.

CM764 also induced an increase in ATP levels of treated cells compared with untreated cells, further indicating metabolic stimulation (Fig. 8). However, this increase was modest ( $\sim 13 \%$ increase in ATP level compared with untreated control). CM764 also induced extensive reduction of ROS in SK-N$\mathrm{SH}$ neuroblastoma compared with untreated cells (Fig. 9B). This effect was rapid, with near-complete elimination of basal levels of ROS occurring within 4 hours of treatment. Interestingly, Ostenfeld et al. (2005) showed that the sigma-2 agonist siramesine caused an increase in ROS in WEHI-S fibrosarcoma and MCF-7 breast tumor cells that contributed to cell death. In addition, methamphetamine may induce ROS production and cell death in differentiated NG108-15 neuroblastoma-glioma hybrid cells via activation of sigma-2 receptors that is antagonized by SN79 (Kaushal et al., 2014).
These opposing effects on ROS by sigma-2 ligands are consistent with the notion of bifurcating toxic and nontoxic pathways mediated by sigma- 2 receptors.

The modest increase in ATP levels and NADH could possibly be explained by the hypothesis that CM764 induces stimulation of glycolysis, rather than oxidative phosphorylation. Stimulation of glycolysis would add only a small amount of both of these factors in comparison with the highly efficient production of ATP and increased reduction of $\mathrm{NAD}^{+}$occurring

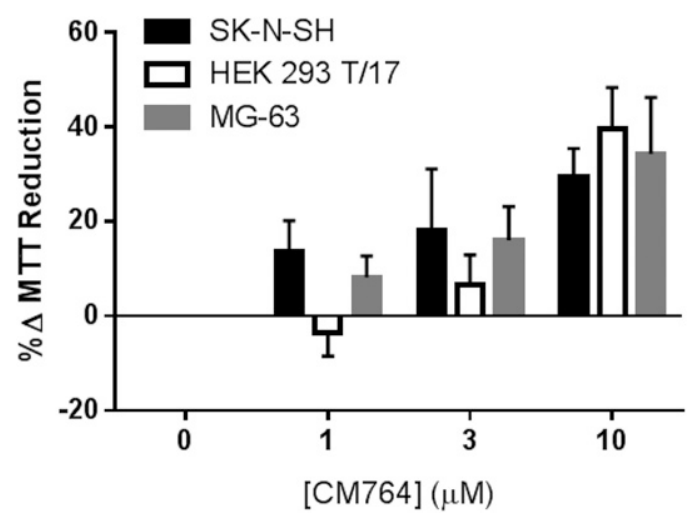

Fig. 12. Effect of CM764 treatment across cell types of different tissues. Human SK-N-SH neuroblastoma, HEK293T human embryonic kidney cells, and MG-63 human osteosarcoma cells were treated with the indicated dose of CM764 for 24 hours. MTT assay was then carried out as described in Materials and Methods. CM764 treatment induced an increase in reduction of MTT reagent in all three cell types examined. These data indicate that the effect of CM764 observed in the neuroblastoma is not a cell line-specific effect but is consistent across multiple cell types, both cancerous and noncancerous. Results are shown as an average percent change in MTT reduction \pm S.D. compared with an untreated control in each cell line for at least three independent experiments, with each experiment performed with five replicates per condition. 
by oxidative phosphorylation. The reduction in ROS observed in response to treatment with CM764 is also consistent with a hypothesis that CM764 induces stimulation of glycolysis since the glycolytic pathway can reduce ROS in two ways. First, a product of glycolysis is pyruvate, which has antioxidant properties. Second, preferential use of glycolysis for ATP production can reduce oxidative phosphorylation, which decreases the amount of oxygen channeled into superoxide formation. Thus, induction of glycolysis by CM764 is consistent with the observed ATP, NADH/NAD ${ }^{+}$, and ROS data.

CM764 induced an increase in HIF $1 \alpha$ protein level, known to be stabilized under conditions of aerobic glycolysis (Fig. 10). Induction of HIF $1 \alpha$ by CM764 treatment is consistent with activation of glycolysis, and has been shown to be induced without hypoxia in such cases. Furthermore, CM764 treatment also induced expression of VEGF, a transcriptional target of HIF $1 \alpha$ (Fig. 11). This suggests that the HIF $1 \alpha$ protein level increase is active protein since the increased expression in VEGF followed $\sim 18$ hours after the first significant observed increase in HIF $1 \alpha$, which occurred after 6 hours of treatment. Taken together, these data suggest that CM764 induces a sigma-2-modulated stimulation of cellular glycolysis under normoxia. This is a novel function of the sigma-2 receptor that is more consistent with observations of sigma-2 receptor expression in rapidly proliferating noncancerous cells such as HEK (Johannessen et al., 2009; Xu et al., 2011) and COS (Monassier et al., 2007; Johannessen et al., 2009) cells, as well as in tumor cells since it may offer protection against damage from ROS. Consistent with this hypothesis, CM764 induced an increase in MTT reduction that matched the increase induced in SK-N-SH neuroblastoma cells when dosed in human embryonic kidney cells and human osteosarcoma cells, indicating that this effect is present across a variety of tumor and noncancerous cell types.

Overexpression of HIF $1 \alpha$ is a common observation in many cancers (Zhong et al., 1999; Talks et al., 2000). HIF1 $\alpha$ allows cells to overcome hypoxic conditions, which are common in the core of tumors and for metastases that may not have an established blood supply. Furthermore, through its transcriptional activation of VEGF, HIF $1 \alpha$ promotes angiogenesis, and therefore oxygen supply for metastatic sites (Lin et al., 2004; Liang et al., 2008; Kim et al., 2014). The novel function of the sigma-2 receptor that our study has revealed is consistent with this role of HIF $1 \alpha$ in rapidly proliferating cancer cells and allows for congruous explanation of the high expression of sigma-2 receptors in the same. Interestingly, sigma-1 receptors have also been linked to HIF $1 \alpha$. The blockade of sigma-1 receptors by the putative antagonist rimcazole in normoxic colorectal and mammary carcinoma cells increases HIF $1 \alpha$, but with a cytotoxic effect in this case (Achison et al., 2007). Thus, regulation of HIF $1 \alpha$ by sigma- 1 and sigma-2 receptor subtypes may be complex, with different viability outcomes depending on cell type and sigma ligand.

It has been proposed that the sigma-2 receptor binding site resides within the PGRMC1 protein complex (Xu et al., 2011). However, whether the sigma-2 receptor and PGRMC1 are one in the same molecule remains controversial (Abate et al., 2015; $\mathrm{Chu}$ et al., 2015). Furthermore, the physiologic effects of PGRMC1 activation have largely been shown to promote cell survival and inhibit apoptosis, which is in direct contrast to classic proapoptotic models of sigma-2 receptor activation (Lösel et al., 2008; Neubauer et al., 2009; Ahmed et al., 2010;
Peluso et al., 2010). Interestingly, activation of PGRMC1 by cell-impermeable progesterone was shown to significantly stimulate VEGF gene expression in MCF-7 cells (Neubauer et al., 2009). The lack of (+)-pentazocine activity and the data shown in Fig. 5 indicate that the pharmacological profile of CM764-induced stimulation of MTT reduction is consistent with mediation by sigma-2 receptors. However, stimulation of VEGF expression by CM764 resembles an effect of PGMRC1 activation (Neubauer et al., 2009). In view of the controversy over the identity of the sigma-2 receptor, there are three possible explanations for the data reported here: 1) the sigma2 receptor is the binding site of PGRMC1, with bifurcating apoptotic and nonapoptotic pathways being initiated from a single sigma-2/PGRMC1 receptor entity, depending on the specific ligand involved; 2) PGRMC1 and sigma-2 receptors are distinct molecules, but have overlapping pharmacological profiles allowing some sigma-2 ligands to have effects at PGRMC1; or 3) PGRMC1 and sigma-2 receptors are distinct entities with distinct pharmacological profiles, but binding of some compounds to sigma-2 receptors results in complexation with PGRMC1 and activation of nontoxic PGRMC1 signaling events. Distinguishing these possibilities will require further investigation. It should be mentioned here that several other SN79 analogs with high sigma-2 affinity are also able to stimulate MTT reduction (Nicholson, et al.; manuscript in preparation). In deference to the observed pharmacological profile, we have referred to the effects described herein as being sigma-2 receptor mediated.

In conclusion, this study unveils a novel metabolically stimulative, nontoxic sigma-2 receptor function. It is consistent with an evolutionary benefit to upregulation of sigma-2 receptors in cancer cells and rapidly proliferating noncancerous cells, suggesting potential for protection against oxidative damage, hypoxic conditions, and stimulation of angiogenesis via VEGF production.

\section{Acknowledgments}

The authors thank Dr. Elena Oancea (Brown University, Providence, RI) for the generous gift of HEK 293 T/17 cells. We thank Dr. Eric Darling (Brown University, Providence, RI) for the generous gift of MG-63 osteosarcoma cells.

\section{Authorship Contributions}

Participated in research design: Nicholson, Bowen.

Conducted experiments: Nicholson.

Contributed new reagents or analytic tools: Mesangeau, McCurdy. Performed data analysis: Nicholson.

Wrote or contributed to the writing of the manuscript: Nicholson, Bowen.

\section{References}

Abate C, Niso M, Infantino V, Menga A, and Berardi F (2015) Elements in support of the 'non-identity' of the PGRMC1 protein with the $\sigma 2$ receptor. Eur J Pharmacol 758:16-23.

Achison M, Boylan MT, Hupp TR, and Spruce BA (2007) HIF-1 $1_{\alpha}$ contributes to tumour-selective killing by the sigma receptor antagonist rimcazole. Oncogene $\mathbf{2 6}$ : 1137-1146.

Ahmed IS, Rohe HJ, Twist KE, Mattingly MN, and Craven RJ (2010) Progesterone receptor membrane component 1 (Pgrmc1): a heme-1 domain protein that promotes tumorigenesis and is inhibited by a small molecule. J Pharmacol Exp Ther 333: $564-573$.

Berridge MV, Herst PM, and Tan AS (2005) Tetrazolium dyes as tools in cell biology: New insights into their cellular reduction. Biotechnol Annual Rev 11:127-152.

Cassano G, Gasparre G, Niso M, Contino M, Scalera V, and Colabufo NA (2009) F281, synthetic agonist of the sigma-2 receptor, induces $\mathrm{Ca}^{2+}$ efflux from the endoplasmic reticulum and mitochondria in SK-N-SH cells. Cell Calcium 45:340-345.

Cesen MH, Repnik U, Turk V, and Turk B (2013) Siramesine triggers cell death through destabilisation of mitochondria, but not lysosomes. Cell Death Dis 4:e818. 
Chaki S, Tanaka M, Muramatsu M, and Otomo S (1994) NE-100, a novel potent sigma ligand, preferentially binds to sigma 1 binding sites in guinea pig brain. Eur $J$ Pharmacol 251:R1-R2.

Chu UB, Mavlyutov TA, Chu M-L, Yang H, Schulman A, Mesangeau C, McCurdy CR, Guo L-W, and Ruoho AE (2015) The sigma-2 receptor and progesterone receptor membrane component 1 are different binding sites derived from independent genes. EBioMedicine http://dx.doi.org/10.1016/j.ebiom.2015.10.017.

Crawford KW and Bowen WD (2002) Sigma-2 receptor agonists activate a novel apoptotic pathway and potentiate antineoplastic drugs in breast tumor cell lines. Cancer Res 62:313-322.

Curtarello M, Zulato E, Nardo G, Valtorta S, Guzzo G, Rossi E, Esposito G, Msaki A, Pasto A, Rasola A, Persano L, Ciccarese F, Bertorelle R, Todde S, Plebani M, Schroer H, Walenta S, Mueller-Klieser W, Amadori A, Moresco RM, and Indraccolo S (2015) VEGF-targeted therapy stably modulates the glycolytic phenotype of tumor cells Cancer Res 75(1):120-133.

Dery MC, Michaud MD, and Richard DE (2005) Hypoxia-inducible factor 1: regulation by hypoxic and non-hypoxic activators. IJBCB 37:535-540.

Garcia DR (2012) Sigma-2 receptor-mediated cytotoxicity and calcium signaling: Evidence for bifurcating pathways. Ph.D. thesis, Brown University, Providence, RI

Garcia DR and Bowen WD (2010) Sigma-2 receptor-mediated apoptosis and calcium signaling: Are they bifurcating pathways? Program No. 470.17. 2010 Neuroscience Meeting Planner. San Diego, CA: Society for Neuroscience, 2010. Online.

Hayashi T and Su TP (2003) Intracellular dynamics of $\sigma-1$ receptors ( $\sigma_{1}$ binding sites) in NG108-15 cells. J Pharmacol Exp Ther 306:726-733.

Hayashi T and Su TP (2007) Sigma-1 receptor chaperones at the ER-mitochondrion interface regulate $\mathrm{Ca}^{2+}$ signaling and cell survival. Cell 131:596-610.

Hazelwood S and Bowen WD (2006) Sigma-2 receptor-mediated apoptosis in human SK-N-SH neuroblastoma cells: Role of lipid rafts, caspases, and mitochondrial depolarization. Proc Am Assoc Cancer Res 47:4932.

Hellewell SB and Bowen WD (1990) A sigma-like binding site in rat pheochromocytoma (PC12) cells: decreased affinity for (+)-benzomorphans and lower molecular weight suggest a different sigma receptor form from that of guinea pig brain. Brain Res 527:244-253.

Hellewell SB, Bruce A, Feinstein G, Orringer J, Williams W, and Bowen WD (1994) Rat liver and kidney contain high densities of sigma 1 and sigma 2 receptors: characterization by ligand binding and photoaffinity labeling. Eur $J$ Pharmacol 268:9-18.

Johannessen M, Ramachandran S, Riemer L, Ramos-Serrano A, Ruoho AE and Jackson MB (2009) Voltage-gated sodium channel modulation by sigmareceptors in cardiac myocytes and heterologous systems. Am J Physiol Cell Physiol 296:C1049-C1057.

Kaushal N, Robson MJ, Rosen A, McCurdy CR, and Matsumoto RR (2014) Neuroprotective targets through which 6-acetyl-3-(4-(4-(4-fluorophenyl)piperazin-1yl)butyl)benzo[d] oxazol-2(3H)-one (SN79), a sigma receptor ligand, mitigates the effects of methamphetamine in vitro. Eur J Pharmacol 724:193-203.

Kaushal N, Robson MJ, Vinnakota H, Narayanan S, Avery BA, McCurdy CR, and Matsumoto RR (2011) Synthesis and pharmacological evaluation of 6-acetyl-3(4-(4-(4-fluorophenyl)piperazin-1-yl)butyl)benzo[d]oxazol-2(3H)-one (SN79), a cocaine antagonist, in rodents. AAPS J 13:336-346.

Kaushal N, Seminerio MJ, Robson MJ, McCurdy CR, and Matsumoto RR (2012) Pharmacological evaluation of SN79, a sigma $(\sigma)$ receptor ligand, against methamphetamine-induced neurotoxicity in vivo. Eur Neuropsychopharmacol $\mathbf{2 3}$ 960-971.

Kim A, Im M, Yim NH, and Ma JY (2014) Reduction of metastatic and angiogenic potency of malignant cancer by Eupatorium fortunei via suppression of MMP-9 activity and VEGF production. Sci Rep 4:6994.

Kuschel A, Simon P, and Tug S (2012) Functional regulation of HIF-1 $\alpha$ under normoxia-is there more than post-translational regulation?. J Cell Physiol 227(2): $514-524$.

Liang X, Yang D, Hu J, Hao X, Gao J, and Mao Z (2008) Hypoxia inducible factoralpha expression correlates with vascular endothelial growth factor-C expression and lymphangiogenesis/angiogenesis in oral squamous cell carcinoma. Anticancer Res 28:1659-1666.

Lin C, McGough R, Aswad B, Block JA, and Terek R (2004) Hypoxia induces HIF-1 $\alpha$ and VEGF expression in chondrosarcoma cells and chondrocytes. J Orthop Res 22 1175-1181.
Liu Y, Peterson DA, Kimura H, and Schubert D (1997) Mechanism of cellular 3-(4,5dimethylthiazol-2-yl)-2,5-diphenyltetrazolium bromide (MTT) reduction. J Neurosci 69(2):581-93.

Lösel RM, Besong D, Peluso JJ, and Wehling M (2008) Progesterone receptor membrane component 1-many tasks for a versatile protein. Steroids 73:929-934.

Mach RH, Zeng C, and Hawkins WG (2013) The $\sigma 2$ receptor: a novel protein for the imaging and treatment of cancer. J Med Chem 56:7137-7160.

Matsumoto RR, Bowen WD, Tom MA, Vo VN, Truong DD, and De Costa BR (1995) Characterization of two novel sigma receptor ligands: antidystonic effects in rats suggest sigma receptor antagonism. Eur J Pharmacol 280:301-310.

McCurdy CR, Mesangeau C, Matsumoto RR, Poupaert JH, Avery BA and Abdelazeem AHA (2014) inventers, The University Of Mississippi and L'Universite Catholique De Louvain, assignees. Highly selective sigma receptor ligands. U.S. patent 8686008 B2. 2014 Apr 1.

Monassier L, Manoury B, Bellocq C, Weissenburger J, Greney H, Zimmermann D, Ehrhardt JD, Jaillon P, Baró I, and Bousquet P (2007) $\sigma_{2}$-Receptor ligandmediated inhibition of inwardly rectifying $\mathrm{K}^{+}$channels in the heart. $J$ Pharmacol Exp Ther 322:341-350.

Neubauer H, Adam G, Seeger H, Mueck AO, Solomayer E, Wallwiener D, Cahill MA and Fehm T (2009) Membrane-initiated effects of progesterone on proliferation and activation of VEGF in breast cancer cells. Climacteric 12:230-239.

Nicholson H, Comeau A, Mesangeau C, McCurdy CR, and Bowen WD (2015) Characterization of CM572, a selective irreversible partial agonist of the sigma-2 receptor with antitumor activity. J Pharmacol Exp Ther 354:203-212.

Ostenfeld MS, Fehrenbacher N, Høyer-Hansen M, Thomsen C, Farkas T, and Jäättelä M (2005) Effective tumor cell death by $\sigma-2$ receptor ligand siramesine involves lysosomal leakage and oxidative stress. Cancer Res 65:8975-8983.

Peluso JJ, Liu X, Gawkowska A, Lodde V, and Wu CA (2010) Progesterone inhibits apoptosis in part by PGRMC1-regulated gene expression. Mol Cell Endocrinol 320: $153-161$.

Shoghi KI, Xu J, Su Y, He J, Rowland D, Yan Y, Garbow JR, Tu Z, Jones LA, and Higashikubo R, et al. (2013) Quantitative receptor-based imaging of tumor proliferation with the sigma-2 ligand ${ }^{18}{ }^{18} \mathrm{~F}$ ISO-1. PLoS One 8:e74188.

Talks KL, Turley H, Gatter KC, Maxwell PH, Pugh CW, Ratcliffe PJ, and Harris AL (2000) The expression and distribution of the hypoxia-inducible factors HIF- $1 \alpha$ and HIF-2 $\alpha$ in normal human tissues, cancers, and tumor-associated macrophages. Am $J$ Pathol 157:411-421.

Tsai SY, Hayashi T, Mori T, and Su TP (2009) Sigma-1 receptor chaperones and diseases. Cent Nerv Syst Agents Med Chem 9:184-189.

Vilner BJ and Bowen WD (2000) Modulation of cellular calcium by sigma-2 receptors: release from intracellular stores in human SK-N-SH neuroblastoma cells. $J$ Pharmacol Exp Ther 292:900-911.

Vilner BJ, John CS, and Bowen WD (1995) Sigma-1 and sigma-2 receptors are expressed in a wide variety of human and rodent tumor cell lines. Cancer Res $\mathbf{5 5}$ : $408-413$.

Wheeler KT, Wang LM, Wallen CA, Childers SR, Cline JM, Keng PC, and Mach RH (2000) Sigma-2 receptors as a biomarker of proliferation in solid tumours. $\mathrm{Br} J$ Cancer 82:1223-1232.

Xu J, Zeng C, Chu W, Pan F, Rothfuss JM, Zhang F, Tu Z, Zhou D, Zeng D, and Vangveravong S, et al. (2011) Identification of the PGRMC1 protein complex as the putative sigma-2 receptor binding site. Nat Commun 2:380.

Zeng C, Rothfuss J, Zhang J, Chu W, Vangveravong S, Tu Z, Pan F, Chang KC, Hotchkiss R, and Mach RH (2012) Sigma-2 ligands induce tumour cell death by multiple signalling pathways. $\mathrm{Br}$ J Cancer 106:693-701.

Zeng C, Rothfuss JM, Zhang J, Vangveravong S, Chu W, Li S, Tu Z, Xu J, and Mach $\mathrm{RH}$ (2014) Functional assays to define agonists and antagonists of the sigma-2 receptor. Anal Biochem 448:68-74.

Zhong H, De Marzo AM, Laughner E, Lim M, Hilton DA, Zagzag D, Buechler P, Isaacs WB, Semenza GL, and Simons JW (1999) Overexpression of hypoxiainducible factor $1 \alpha$ in common human cancers and their metastases. Cancer Res $\mathbf{5 9}$ $5830-5835$.

Address correspondence to: Dr. Wayne D. Bowen, Department of Molecular Pharmacology, Physiology, and Biotechnology, Brown University, 171 Meeting Street, Box G-B389, Providence, RI 02912. E-mail: Wayne_Bowen@brown.edu 